\title{
Synthesis and characterization of novel biodegradable water dispersed poly(ether-urethane)s and their MWCNT-AS nanocomposites functionalized with aspartic acid as dispersing agent
}

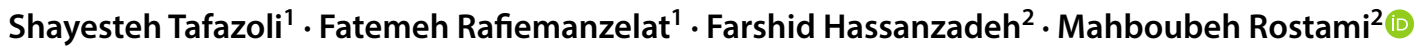

Received: 7 February 2018 / Accepted: 25 July 2018 / Published online: 8 September 2018

(c) Iran Polymer and Petrochemical Institute 2018

\begin{abstract}
New biodegradable poly(ether-urethane)s (PEU)s were synthesized via the reaction of $L$-leucine anhydride cyclo-peptide, polyethylene glycol-1000 and hexamethylene diisocyanate. Then, they were end-functionalized with aspartic acid (AS) as a dispersing agent and were dispersed in water. MWCNTs were also functionalized by AS under microwave irradiation. Polymer/MWCNT-AS composites and polymer/MWCNT-AS water dispersed composites were prepared through an ultrasoundassisted method. We have designed these PEUs with two different structural architectures (PA1and PA2) which can be readily dispersed in water (PA1-D and PA2-D). The structure and properties of the polymers, MWCNTs-AS and PEUs/MWCNTsAS composites were investigated by FTIR and NMR spectroscopy methods and FE-SEM, TEM and TGA techniques. The particle sizes of the resulting PA1-D and PA2-D dispersions were in the range of 200-300 nm. The results showed that by increasing MWCNT-AS loading, the degradation rate and particle sizes of the dispersed composites decreased, while thermal stability and dispersion stability of the composite systems increased. The degradation tests of polymers and their composites in PBS at $37^{\circ} \mathrm{C}$ after 10 days showed weight losses ranging from 23 to 44 and $17-37 \%$, respectively. The cytotoxicity study of polymers using the direct-contact test on L929 mouse fibroblast cell line showed no toxicity. Other properties such as thermal stability, dispersion's particle size, degradation rate and morphology of the composites were studied, and the effect of simultaneous dispersion of MWCNTs-AS and PEUs in water on the properties of the resulting mixtures was studied. We suggest that these polymers have tunable properties which may potentially be considered for drug carriers' studies.
\end{abstract}

Keywords Copoly(ether-urethane) $\cdot$ Water dispersion $\cdot L$-leuceine anhydride cyclopeptid $\cdot$ Aspartic acid $\cdot$ Biofunctionalized MWCNT $\cdot$ Biodegradable

Fatemeh Rafiemanzelat and Mahboubeh Rostami have contributed equally to this article.

Electronic supplementary material The online version of this article (https://doi.org/10.1007/s13726-018-0655-0) contains supplementary material, which is available to authorized users.

Fatemeh Rafiemanzelat

frafiemanzelat@sci.ui.ac.ir

$\triangle$ Mahboubeh Rostami

m.rostami@pharm.mui.ac.ir

1 Organic Polymer Chemistry Research Laboratory, Department of Chemistry, University of Isfahan, Isfahan 81746-73441, Islamic Republic of Iran

2 Department of Medicinal Chemistry, School of Pharmacy and Pharmaceutical Sciences, Novel Drug Delivery Systems Research Centre, Isfahan University of Medical Sciences, Isfahan, Islamic Republic of Iran

\section{Introduction}

For their excellent physicochemical properties, polyurethanes (PU)s have been extensively used in biomedical applications [1-3]. Some of these outstanding applications include heart valves, aortic grafts, pacing lead insulation, catheters, temporary scaffolds and controlled release systems of active pharmaceuticals [4].

One of the benefits of PUs is the possibility of synthesizing them using various subunit components. PUs are an arrangement of alternating hard and soft segments, and by varying their chemical compositions, their properties can be tuned [5]. This strategy enables us to create different chain architectures which are applicable in manufacturing drug delivery systems such as micelles, hydrogels, nanoparticles and microsphere, as well as different release triggered systems. It is easy to insert the hydrophilic 
and hydrophobic segments into the PU chains to interact with both hydrophilic and hydrophobic drugs [6-8]. There are many examples of different PU drug carriers. For instance, Zhang et al. synthesized the amphiphilic poly(lactic acid)-polyurethane having carboxylic groups via step polycondensation reaction. They prepared PULA micelles and studied the degradation profile of micelles. They showed the effect of the carboxylic acid array of the chains on the degradation rate and the drug-releasing rate [9]. Reddy et al. synthesized segmented poly(urethaneurea) based on aliphatic diisocyanate 2,6-diisocyanatomethyl caproate(lysine-based diisocyanate) with poly( $\varepsilon$ caprolactone diol)s. They also studied degradation of these polymers in alkaline solution and in vitro drug release of sulfamethoxazole in $\mathrm{pH} 7.4$ buffer [10]. Another example in this field is a novel $\mathrm{pH}$-sensitive multifunctional polyurethane micelles having hydrazone linkers which were acid-cleavable. The synthesized poly( $\varepsilon$-caprolactone)hydrazone-poly-(ethylene glycol)-hydrazone-poly( $\varepsilon$ caprolactone) diol (PCL-Hyd-PEG-Hyd-PCL) could be a good choice as a multifunctional biodegradable micelle [11].

Due to the control of the release of volatile organic compounds (VOC), preparation of waterborne PUs (WBPUs) has been one of the most economical and environmental-friendly fields of polymerization [12]. WBPUs can be synthetized either in non-ionomer or ionomer forms. Non-ionomer types contain hydrophilic soft blocks such as PEG, whereas the ionomer types contain pendant acid [commonly dimethylolpropionic acid (DMPA)], or tertiary amine groups, which are neutralized to form carboxylate or ammonium salts [13].

The biodegradability of PUs is generally achieved by incorporating labile and hydrolysable functional groups into the polymer backbones [14]. It has been shown that copolymers consisting of PEG and peptide sequences are highly water-soluble, degradable, non-immunogenic and relatively non-toxic [15]. The hydrophilic nature of PEG and its derivatives results in avoiding absorption by serum proteins and prevents recognition of the micelles by the cells of the reticuloendothelial system after intravenous injection. This is an undeniable benefit of PUs containing PEG derivatives for biomedical usages [16]. Diisocyanates and chain extenders which are typically used as the hard segment in PUs are not biocompatible. These compounds produce toxic and carcinogenic compounds such as aromatic diamines after degradation. Therefore, PUs based on aliphatic diisocyanates or bio-based diisocyanates are preferred for in vivo applications [17-20].

Recently, the synthesis of polymers containing amino acids residue has been an interesting field of study. It has been shown that the presence of amino acid functionality can lead to polymers with improved solubility, biocompatibility and biodegradability [21].
2,5-Diketopiperazines are subject of interest due to their biological properties such as the inhibition of plasminogen activator-inhibitor- 1 and alteration of cardiovascular and blood-clotting functions [22-24]. They have also been interesting as anti-tumoral, antiviral, antifungal and antibacterial agents [25-27]. Some of the chemical properties of 2,5-diketopiperazines such as resistance to proteolysis, simulating of peptidic pharmacophoric groups, donor and acceptor properties for hydrogen bonding and favoring interactions with biological targets are very interesting for pharmaceutical chemistry studies $[28,29]$. Amino acid anhydrides prepared from natural amino acids are kinds of 2,5-diketopiperazines, which may be good candidates for the synthesis of polymers with interesting biodegradability and bioactivity properties [30, 31].

Carbon nanotubes (CNTs) have recently been raised as one of the most advanced nano-carriers for the highly efficient delivery of drugs and biomolecules. They can be conjugated covalently or non-covalently with drugs, biomolecules and nanoparticles. It has been shown that functionalized CNTs exhibit very low toxicity and are not immunogenic. Thus, they could be motivating carriers with an excellent capability for the development of a new-generation of drug delivery systems [32-34]. On the other hand, dispersing CNTs in a polymer matrix is one of the most critically essential features in preparation of CNT/polymer nanocomposites. One of the considerable improvements in the dispersion of CNTs in a polymer matrix can be attained through bio-functionalization of CNTs. This can lead to the better dispersion of CNTs in water, as well as in polymer matrix [35-37].

In this work, $L$-leucine anhydride cyclo-peptide (LAC), as an amino acid, and 2,5-diketopiperazine based monomer together with PEG-1000, which have suitable properties for the preparation of non-immunogenic and biodegradable polymers, are utilized to synthesize nontoxic and biodegradable polymers. Using hexamethylene diisocyanate (HDI), as an aliphatic diisocyanate, it is expected to prevent forming toxic compounds such as aromatic amines which are formed after the degradation of the aromatic diisocyanates. In addition, it was anticipated that the application of AS instead of DMPA, as the ionic dispersing agent, played a vital role in the biofunctionalization of the chains for dispersing them in water. We used multiple strategies, such as surface functionalization of MWCNTs and ultrasonication solution blending procedure as fast, green and economical methods, to disperse the MWCNTs-AS in the polymer matrix. Furthermore, compatibility of these functionalized PEUs as a polymer matrix for aspartic acid-modified MWCNTs and their simultaneous dispersion in water are discussed in this work, for the first time. The focus of the current work was on the preparation of the polymers, polymer water dispersions, polymer composites and polymer composites water dispersions. Then, the 
properties of the polymers and polymer water dispersions were studied and the effects of MWCNT-AS on thermal, degradation and dispersion characteristics of the polymer composites were studied. It was expected that the modification of MWCNTs by AS and the polymer, increased water disperseability of CNTs and mutually MWCNT-AS modified thermal and dispersion characteristics and degradation rate of the polymers.

\section{Experimental}

\section{Materials}

All chemicals were purchased from Sigma-Aldrich and Merck (Germany). 1,6-Hexamethylene diisocyanate (HDI) (Merck, Germany) was used as received. Poly(ethylene glycol) (PEG) (Merck, Germany, $M_{n}=1000 \mathrm{~g} / \mathrm{mol}$ ) were dried under vacuum at $80{ }^{\circ} \mathrm{C}$ for $6 \mathrm{~h}$. Azeotropic distillation in the presence of dried toluene did not show much improvement in drying PEG according to Karl-Fisher test. $L$-Leucine and aspartic acid (AS) (Merck, Germany) were dried under vacuum at $80^{\circ} \mathrm{C}$ for $3 \mathrm{~h}$. Ethylene glycol (EG) (Merck, Germany) and $N$-methyl-2-pyrrolidone (NMP) (Merck, Germany) were distilled under reduced pressure over dried $\mathrm{BaO}$ (Sigma-Aldrich, Germany). Dimethyl sulfoxide (DMSO) (Merck, Germany) and dimethylformamide (DMF) (Merck, Germany), dimethylacetamide (DMAc) and ethanol together with sodium hydrogen carbonate $\left(\mathrm{NaHCO}_{3}\right)$ (Merck, Germany) were used as received. MWCNT (diameter $10-20 \mathrm{~nm}$, length $30 \mu \mathrm{m}$, purity > $95 \mathrm{wt} \%$ ) was purchased from Neutrino Co. (Iran). $\mathrm{H}_{2} \mathrm{SO}_{4} 98 \%, \mathrm{KMnO}_{4}$, and $\mathrm{HCl}$ from Merck (Germany) were used for the preparation of oxidized MWCNTs.

\section{Apparatus and measurements}

FTIR spectra were recorded on a Jasco FTIR 6300 spectrophotometer (Japan), and vibrational frequencies were reported in wavenumber $\left(\mathrm{cm}^{-1}\right)$. Band intensities and designations were assigned as weak (w), medium (m), shoulder (sh), strong (s) broad (br), stretching (str) and bending (bend).

${ }^{1} \mathrm{HNMR}(400 \mathrm{MHz})$ spectra were recorded on a Bruker, Avance 400 instrument (Germany) in dimethyl sulfoxide $\left(\mathrm{DMSO}-d_{6}\right.$ ) at room temperature (RT). Multiplicities of proton resonance were designated as singlet (s), doublet (d), doublet of doublet (dd), multiplet (m) and broad (br).

Inherent viscosities $\left(\eta_{\text {inh }}\right)$ were measured by a standard procedure using an Ostwald glass capillary (U-tube) viscometer (UK) at RT and concentration of $0.4(\mathrm{~g} / \mathrm{dL})$ in DMF.
For measuring the particle size and the surface charge of particles (ZP), we used Malvern Zetasizer ZEN 3600 (UK), and all measurements were carried out at RT.

For the assessment of polymer surface, before and after degradation test, atomic force microscopy (AFM) (DME Model, Germany-Dual Scope DS M95) instrument was used. All micrographs were presented in top-view at RT, with no filtering to ensure the quality of images. The samples were finely ground and diluted with methanol, after that, dispersed on a microscope slide and studied by AFM.

The cell cytotoxicity of the samples was assessed based on the ISO-10993-5:2009 standard protocol. Transmission electron microscopy (TEM) images were also provided by a Philips CM 120 microscope (Germany); the instrument was adjusted at $100 \mathrm{kV}$. The morphologies of the functionalized MWCNTs and PEU/MWCNT-AS were studied using field emission scanning electron microscopy (FESEM). The micrographs were obtained at $15 \mathrm{kV}$ using a HITACHI S-4160 instrument (Tokyo, Japan).

The thermal stabilities of MWCNTs, PEUs and PEU/ MWCNT-AS nanocomposites were established by thermogravimetric analysis technique (TGA) (STA503 TGA, BahrThermoanalyse $\mathrm{GmbH}$, Hüllhorst, Germany) in the nitrogen atmosphere (flow rate $60 \mathrm{~cm}^{3} / \mathrm{min}$ ). A heating rate of $10^{\circ} \mathrm{C} /$ min was applied in each experiment.

A Samsung microwave oven $(2450 \mathrm{MHz}, 900 \mathrm{~W}$ ) (Seoul, South Korea) was used for the functionalization of MWCNTs. The composites dispersions were prepared using a MISONIX ultrasonic XL-2000 SERIES (Raleigh, North Carolina, USA) instrument. Ultrasonic irradiation was performed with the probe of the ultrasonic horn being immersed directly in the solution with the frequency of $2.25 \times 10^{4} \mathrm{~Hz}$ and the power of $100 \mathrm{~W}$.

\section{Synthesis of PEUs}

\section{PEU copolymer with one aspartic acid-end cap (methodA1)}

A typical preparation method of PEUs, by a three-step polymerization route was as follows: in a dried $25 \mathrm{~mL}$ twonecked round bottom flask equipped with a $\mathrm{N}_{2}$ balloon and magnetic stirrer, PEG $\left(0.442 \mathrm{~g}, 4.420 \times 10^{-4} \mathrm{~mol}\right)$ and NMP $(0.30 \mathrm{~mL})$ were stirred at $40^{\circ} \mathrm{C}$ for $10 \mathrm{~min}$ to obtain a homogeneous solution; then HDI $\left(0.142 \mathrm{~mL}, 8.840 \times 10^{-4} \mathrm{~mol}\right)$ was added. The solution was heated between 40 and $60{ }^{\circ} \mathrm{C}$ for $1 \mathrm{~h}$.

Then, the reaction mixture was heated up to $70{ }^{\circ} \mathrm{C}$ and kept at this temperature for $2 \mathrm{~h}$, then was heated and kept at $80^{\circ} \mathrm{C}$ for $4 \mathrm{~h}$ and finally the temperature was reached to $90{ }^{\circ} \mathrm{C}$ and kept for $8 \mathrm{~h}$. Afterwards, LAC $(0.100 \mathrm{~g}$, $4.420 \times 10^{-4} \mathrm{~mol}$ ) which was synthesized by the same 
procedure reported earlier [31] and $0.4 \mathrm{~mL}$ NMP were heated up to $120^{\circ} \mathrm{C}$ and added to the reaction mixture. The temperature was kept at $120^{\circ} \mathrm{C}$ for $10 \mathrm{~min}$ to dissolve LAC completely. Then, the temperature was reduced to $60{ }^{\circ} \mathrm{C}$, and the reaction was preceded at this temperature for $1 \mathrm{~h}$.

After this step, the reaction was kept at temperature between 80 and $100{ }^{\circ} \mathrm{C}$ over a period of $9 \mathrm{~h}$. Then, the temperature was reduced to $60{ }^{\circ} \mathrm{C}$, and a solution of AS $\left(0.058 \mathrm{~g}, 4.420 \times 10^{-4} \mathrm{~mol}\right)$ in hot DMSO $(1 \mathrm{~mL})$ was added to the reaction mixture (AS is dissolved in DMSO better than in NMP). Subsequently, the reaction mixture was heated further at $80{ }^{\circ} \mathrm{C}$ for $4 \mathrm{~h}$ and at $90{ }^{\circ} \mathrm{C}$ for another $4 \mathrm{~h}$. Then, the viscous solution was poured into $5 \mathrm{~mL}$ distilled water when FTIR monitoring showed NCO consumption by fading its peak at $2270 \mathrm{~cm}^{-1}$.

After shaking and stirring for $30 \mathrm{~min}$, the precipitated polymer was isolated by filtration, dried at $50{ }^{\circ} \mathrm{C}$ for $2 \mathrm{~h}$ under vacuum to give $0.155 \mathrm{~g}(21 \%)$ of the polymer. The inherent viscosity of this polymer was $0.40 \mathrm{dL} / \mathrm{g}$ in DMF, and we evaluated its chemical structure by FTIR and ${ }^{1}$ HNMR techniques.

FTIR absorption bands $\left(\mathrm{cm}^{-1}\right)$ for PA1, $(\mathrm{KBr}): 3432(\mathrm{~m}$, br) NH amid str., 3332 (m,br) NH urea str., 3254 (m) NH urethane str., 3060 (m, br) carboxylic acid O-H str., 2925 (m, br), 2857 (m, br) $\mathrm{CH}$ aliphatic str., $1772(\mathrm{~m}) \mathrm{C}=\mathrm{O}$ urethane str., 1721 (s) $\mathrm{C}=\mathrm{O}$ acid str., 1676 (s) $\mathrm{C}=\mathrm{O}$ urethane-amid str., 1618 (m, sh) $\mathrm{C}=\mathrm{O}$ urea str. 1445 (m) and 1363 (s) C-N str. $1070(\mathrm{~m}), 945(\mathrm{w}) \mathrm{C}-\mathrm{O}-\mathrm{C}$ ether and urethane str., 814 (w) NH bend., $764(\mathrm{~m}) \mathrm{O}=\mathrm{C}-\mathrm{O}, 621(\mathrm{~m}), 566(\mathrm{w}), 490(\mathrm{w})$.

${ }^{1} \mathrm{HNMR}$ peaks, DMSO- $d_{6}$ at RT, $(\delta, \mathrm{ppm}): 1.2(\mathrm{~d}$, $\left.\mathrm{CH}_{3}(\mathrm{a} 1), 6 \mathrm{H}\right), 1.51$ (t, $\left.\mathrm{CH}_{2}(\mathrm{a} 2), 2 \mathrm{H}\right), 1.80(\mathrm{~m}, \mathrm{CH}(\mathrm{a} 3), 1 \mathrm{H})$, 2.8 (dd, m, $\left.\mathrm{CH}_{2}\left(\mathrm{~b}^{\prime}\right), 2 \mathrm{H}\right), 3$ (t, $\left.\mathrm{CH}_{2}(\mathrm{~b}), 4 \mathrm{H}\right), 3.8$ (t, $\mathrm{CH}(\mathrm{c})$, $\mathrm{H}), 4.8\left(\mathrm{~m}, \mathrm{CH}\left(\mathrm{d}^{\prime}\right), 1 \mathrm{H}\right), 5.1\left(\mathrm{t}, \mathrm{CH}_{2}(\mathrm{~d}), 4 \mathrm{H}\right), 6.5-6.9$ (br, NH urethane(e)), 9.4-9.5 (br, NH urea (e')), 11.4 (br, OH $\operatorname{acid}(\mathrm{f}), 2 \mathrm{H})$.

\section{PEU copolymer with two aspartic acid-end caps (method A2)}

A typical preparation method of PEU, by three-step polymerization method was as follows: In a dried $25 \mathrm{~mL}$ twonecked round bottom flask, PEG $\left(0.442 \mathrm{~g}, 4.420 \times 10^{-4} \mathrm{~mol}\right)$ and NMP $(0.30 \mathrm{~mL})$ were mixed by a magnetic stirrer at $40{ }^{\circ} \mathrm{C}$ for $10 \mathrm{~min}$ to obtain a homogeneous solution, then HDI $\left(0.142 \mathrm{~mL}, 8.840 \times 10^{-4} \mathrm{~mol}\right)$ was added. The solution was heated between 40 and $60{ }^{\circ} \mathrm{C}$ for $1 \mathrm{~h}$. Then the reaction mixture was heated at $70{ }^{\circ} \mathrm{C}$ for $2 \mathrm{~h}$, at $80{ }^{\circ} \mathrm{C}$ for $4 \mathrm{~h}$ and finally at $90{ }^{\circ} \mathrm{C}$ for $8 \mathrm{~h}$. Afterward, LAC $(0.050 \mathrm{~g}$, $2.210 \times 10^{-4} \mathrm{~mol}$ ) and $0.4 \mathrm{~mL}$ NMP were added at $120^{\circ} \mathrm{C}$, the temperature was kept at $120^{\circ} \mathrm{C}$ for $10 \mathrm{~min}$ to dissolve LAC. Then, the temperature was reduced to $60^{\circ} \mathrm{C}$, and the reaction was preceded at this temperature for $1 \mathrm{~h}$.
Then, the reaction was heated between 80 and $100{ }^{\circ} \mathrm{C}$ over a period of $9 \mathrm{~h}$. After that, the temperature was reduced to $60{ }^{\circ} \mathrm{C}$, and a solution of AS $\left(0.058 \mathrm{~g}, 4.420 \times 10^{-4} \mathrm{~mol}\right)$ in DMSO $(1 \mathrm{~mL})$ was added into the reaction mixture. Subsequently, the reaction mixture was heated further for $4 \mathrm{~h}$ at $80{ }^{\circ} \mathrm{C}$ and for another $4 \mathrm{~h}$ at $90{ }^{\circ} \mathrm{C}$. Then, the viscous solution of the reaction mixture was poured into $5 \mathrm{~mL}$ distilled water. After shaking and stirring for $30 \mathrm{~min}$, the precipitated polymer was isolated by filtration, dried at $50{ }^{\circ} \mathrm{C}$ for $2 \mathrm{~h}$ under vacuum to give $0.147 \mathrm{~g}(21.1 \%)$ of the polymer. The inherent viscosity of this polymer was $0.42 \mathrm{dL} / \mathrm{g}$ in DMF, and we evaluated its chemical structure by FTIR and ${ }^{1}$ HNMR techniques.

FTIR absorption bands $\left(\mathrm{cm}^{-1}\right)$ for PA2, $(\mathrm{KBr}): 3440(\mathrm{~m}$, br) NH amid str., 3322 (s, br) NH urea str., 3259 (m, sh) NH urethane str., 3101 (m, br) OH acid str., 2910 (m, br), 2862 (m, br) $\mathrm{CH}$ aliphatic str., 1770 (w) $\mathrm{C}=\mathrm{O}$ urethane str., 1701 (s) $\mathrm{C}=\mathrm{O}$ acid str., 1668 (s) $\mathrm{C}=\mathrm{O}$ urethane-amid str., 1620 (m, sh) $\mathrm{C}=\mathrm{O}$ urea str. 1437 and $1343 \mathrm{C}-\mathrm{N}$ str. 1010 (m), 955 (w) $\mathrm{C}-\mathrm{O}-\mathrm{C}$ ether str., 838 (w) NH bend., 755 (m) O=C-O, 641 (m), $560(\mathrm{w}), 496(\mathrm{w})$.

\section{Oxidation of MWCNTs}

To functionalize MWCNTs, we used the acidic $\mathrm{KMnO}_{4}$ solution. First, $2 \mathrm{~g}$ of MWCNTs was dispersed in $120 \mathrm{~mL}$ of $\mathrm{H}_{2} \mathrm{SO}_{4}$ solution $(4.5 \mathrm{M})$ and then $2 \mathrm{~g}$ of $\mathrm{KMnO}_{4}$ was added. The solution was heated at $95{ }^{\circ} \mathrm{C}$ for about $2 \mathrm{~h}$. Then, the suspension was cooled down and filtered. The obtained solid was washed with water, filtered, re-washed with concentrated $\mathrm{HCl}$ to remove the $\mathrm{MnO}_{2}$ byproduct and then re-washed several times. The obtained functionalized MWCNTs (MWCNT-OX) were washed with water repeatedly until the filtrate became neutral and then dried in air at $110{ }^{\circ} \mathrm{C}$ for $18 \mathrm{~h}$.

\section{Functionalization of MWCNTs with aspartic acid}

Aspartic acid was covalently attached to MWCNT-OX surface by the reaction of the free amine group of the AS with carboxylic acid groups on MWCNT-OX [38]. For the amidation reaction $20 \mathrm{~mL}$ of DMAc, $0.20 \mathrm{~g}$ of AS, and $0.3 \mathrm{~mL}$ of ethylene oxide were stirred for $2 \mathrm{~h}$ at $60^{\circ} \mathrm{C}$. Then MWCNTOX $(0.1 \mathrm{~g})$ was added, and the mixture was sonicated for $3 \mathrm{~h}$. This suspension was then poured into a porcelain dish and heated in a microwave oven with an output power of $700 \mathrm{~W}$ up to $120^{\circ} \mathrm{C}$ for $17 \mathrm{~min}$. Then, the resulting suspension was cooled to RT and poured into $200 \mathrm{~mL} \mathrm{HCl}$ solution $(5 \% \mathrm{v} / \mathrm{v})$. The mixture was stirred for $30 \mathrm{~min}$ at RT. Then, the mixture was centrifuged and decanted to remove the solvents. The obtained product named as (MWCNT-AS) was characterized by different techniques such as FTIR, TGA, FESEM, and TEM. 


\section{Water dispersed polymers}

A sample of $0.001 \mathrm{~g}$ of PA1 (PA2) was added into a onenecked round bottom flask equipped with a mechanical stirrer. Then, a solution of $\mathrm{NaHCO}_{3}(0.77 \mathrm{M})$ in deionized water ( $\mathrm{pH} 8$ ) was slowly added under vigorous stirring (8000 rpm) to neutralize $\mathrm{COOH}$ groups of the terminal AS. Because AS has $\mathrm{p} K \mathrm{a}=3.9$ and $\mathrm{p} I=2.77$, in this condition $\mathrm{COOH}$ groups of AS would be neutralized $\left(-\mathrm{COO}^{-}\right)$. The mixture was stirred for $3 \mathrm{~h}$ at $40{ }^{\circ} \mathrm{C}$, and polymer dispersions (PA1-D or PA2-D) with $0.02 \mathrm{wt} \%$ solid content were formed. These polymer dispersions can be purified and separated by centrifuging, and then lyophilized to fine powders. Due to the presence of ionic end functional groups $\left(-\mathrm{COO}^{-}\right)$on the polymer chain termini and hydrophilic PEG segments these powders can be dispersed in pure deionized water again.

\section{PEU/MWCNTs-AS composites and their water dispersion counterparts}

The typical procedure for preparing the PA1/MWCNTs-AS composite was as follows: $0.1 \mathrm{~g}$ PA1 was dissolved in $5 \mathrm{~mL}$ DMF. In other flasks, an amount of MWCNT-AS $(0.5,1$ or $2 \mathrm{wt} \%$ ) was added into $5 \mathrm{~mL} \mathrm{DMF}$, stirred for $3 \mathrm{~h}$ and sonicated for at least $1 \mathrm{~h}$. Then the two mentioned solutions were mixed. The resulting mixture was continuously stirred for $24 \mathrm{~h}$ and then sonicated for $1 \mathrm{~h}$ at RT to obtain a homogenized dispersion of MWCNT-AS and PA1. Subsequently, the mixture was cast onto a Teflon mold, and allowed to dry at RT for $24 \mathrm{~h}$ to form PA1/MWCNT-AS composite film (Scheme 1).

To prepare PA1/MWCNTs-AS water dispersion composite (PA1/MWCNTs-AS)-D the same procedure as mentioned above was followed. After mixing MWCNT-AS/DMF mixture with the solution of PA1 in DMF, the resulting mixture was vigorously stirred for $24 \mathrm{~h}$ and then sonicated for at least $1 \mathrm{~h}$ at RT. Then, a solution of $\mathrm{NaHCO}_{3}(0.77 \mathrm{M}, \mathrm{pH}$ 8 ) in deionized water was slowly added to the former solution under vigorous stirring (8000 rpm) to neutralize the $\mathrm{COOH}$ groups of the terminal AS. Next, the resulting mixture was stirred for $3 \mathrm{~h}$ at $40{ }^{\circ} \mathrm{C}$ and sonicated for at least $2 \mathrm{~h}$ (Scheme 1). The particle sizes and surface potentials of the composites dispersions were determined using Malvern Zetasizer instrument.

\section{Degradation of polymers and their composites in PBS solution}

The hydrolytic degradations of PA1 and PA2 were studied in the phosphate buffered saline (PBS) solution ( $\mathrm{pH} 7.4$ ) at $37{ }^{\circ} \mathrm{C}$, in six replicates $\left[(0.1 \mathrm{M}) \mathrm{Na}_{2} \mathrm{HPO}_{4} / \mathrm{KH}_{2} \mathrm{PO}_{4}\right.$ buffered $(0.9 \mathrm{wt} \%) \mathrm{NaCl}$ solution]. In the experiments, $10 \mathrm{mg}$ of each polymer sample was immersed in $10 \mathrm{~mL}$ of PBS and incubated in an air-circulation oven at $37^{\circ} \mathrm{C}$. The PBS solution

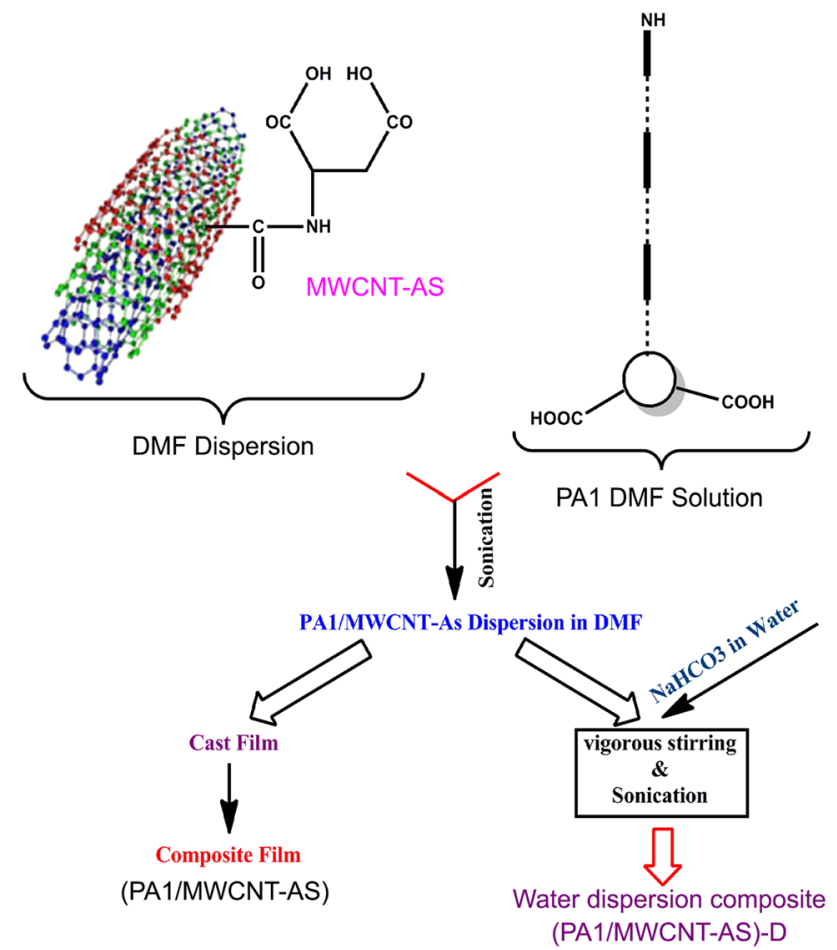

Scheme 1 Preparation routs of PEU/MWCNTs-AS composite and its water dispersion composite

was renewed every other day. After 10 days, the PBS solution phase was removed, and the remaining particles were washed thoroughly with distilled water. Then, they were dried in a vacuum oven at $40{ }^{\circ} \mathrm{C}$ for $2 \mathrm{~h}$ for further studies. The polymers were weighed before and after degradation tests. The percentage of weight loss for each polymer was calculated using the ratio of the mass difference before and after degradation to its original mass.

Similarly, the percentage of viscosity loss for each polymer was determined using the viscosity difference before and after degradation to its initial viscosity. Furthermore, to follow the degradation profile in samples, we investigated the FTIR spectrum of the polymer before and after PBS exposure.

The same method was followed to study the degradation of PA1/MWCNTs-AS and PA2/MWCNTs-AS composites.

\section{Particle size and zeta potential}

The particle sizes and zeta potentials of the waterborne polymers, PA1-D and PA2-D, and their composite dispersions, (PA1/MWCNTs-AS)-D and (PA2/MWCNTs-AS)-D were determined based on direct light scattering method using the Zetasizer. All particle size measurements were performed in deionized water $(\mathrm{pH}$ 8) without dilution immediately after preparation of the polymer dispersions using a He-Ne laser beam at $658 \mathrm{~nm}$ with a scattering angle of $130^{\circ}$. 
Scheme 2 Synthesis of PEU

(PA1) via method A1
STEP 1:

STEP 2:

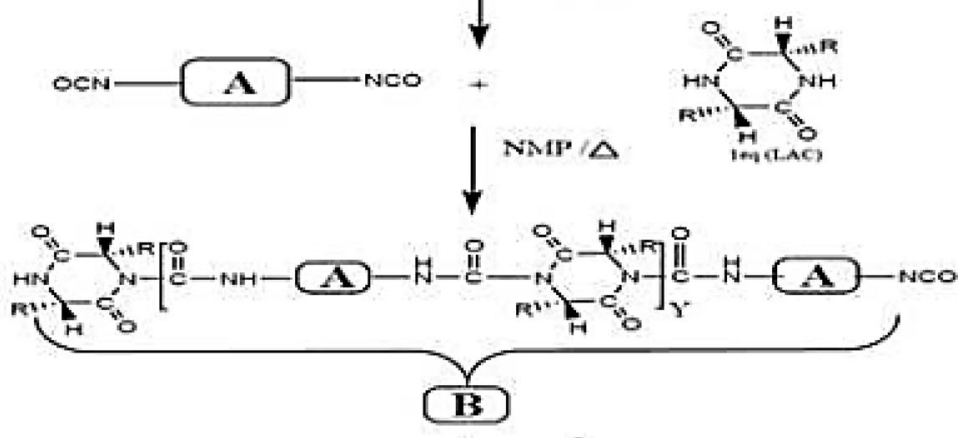

STEP 3:<smiles></smiles>
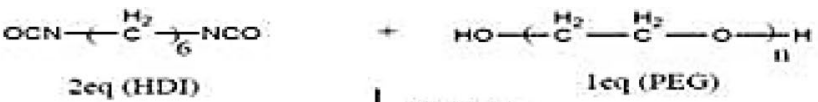

NMT $/ \triangle$

leq (PEG)

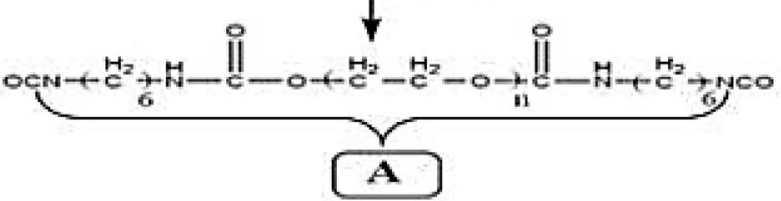

DMso $\triangle$

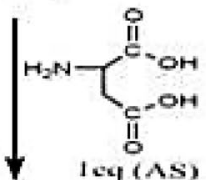

$\mathrm{NMP} / \triangle$
$\mathrm{NMP} / \triangle$

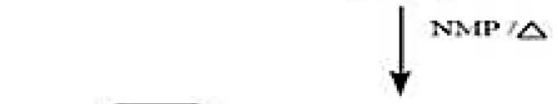

\section{Evaluation of cytotoxicity}

Cytotoxicity of the prepared polymers was evaluated using direct-contact test with L929 fibroblast cell line which was carried out according to ISO-10993-5-2009 standard at Iran Polymer and Petrochemical Institute. L929 cells were cultured in RPMI 1640 supplemented with 10\% FBS, $100 \mathrm{U} /$ $\mathrm{mL}$ penicillin and $100 \mathrm{U} / \mathrm{mL}$ streptomycin in a $\mathrm{CO}_{2}$ incubator supplied with $5 \% \mathrm{CO}_{2}$ at $37{ }^{\circ} \mathrm{C}$. The cultivation was conducted for 24 and $48 \mathrm{~h}$. The optical microscope was used for the observation of cell viability and cell growth or cell contact on the tested polymer powders. Before this test method, the polymer sample was purified via the freeze-thaw process and was sterilized by immersing it in ethanol $70 \%$ and UV irradiation for $10 \mathrm{~min}$. After 24 and $48 \mathrm{~h}$ intervals the culture media of L929 cells on the tested sample were compared with positive and negative controls [39, 40]. 
polymers containing HDI, PEG and AS without LAC. Thus, polymer dispersion in water can be controlled via adjusting hydrophilic and hydrophobic blocks length and blocks distribution along polymer chains. In addition, biodegradation rates of PEUs can be controlled via the amount of incorporation of LAC into the PEUs chains. To summarize, we designed polymer chains so that NCO-terminated soft segments were first established via the reaction of PEG and HDI. Then LAC was added as the chain extender and AS was added as the internal dispersing agent and the functionalizing agent of the polymer chain termini.

PA1 was synthesized through the polymerization reaction of PEG, HDI, LAC and AS, respectively, in NMP via the conventional heating method without any catalyst (Scheme 2). In the first step, the diisocyanate-terminated oligo(ether-urethane)s (intermediate compound A) were prepared as soft segments through the reaction of HDI (2 eq) with PEG-diol (1 eq) (FTIR (Fig. S1, spectrum A) and NCO titration test confirmed it). Then, 1(eq) of LAC was added, and the reaction was continued to afford PEU multi-block

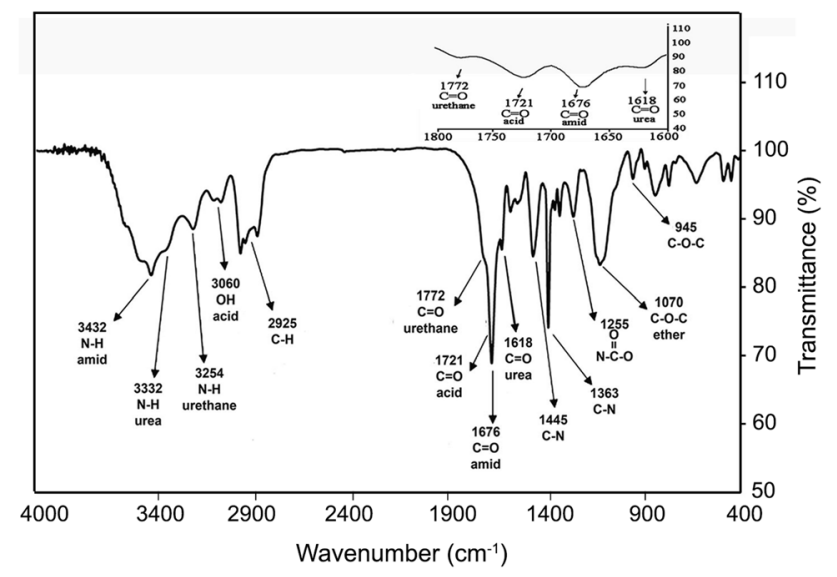

Fig. 1 FTIR (KBr) spectrum of PA1 polymer copolymer containing PEG-HDI soft blocks and LAC-HDI hard blocks with one NCO capped at one end (Scheme 2, intermediate compound B). Then, intermediate compound $\mathrm{B}$ was further reacted with 1(eq) of AS as dispersing agent. Finally, PEU multi-block copolymer chains with two carboxylic acids and one $\mathrm{NH}$ end groups were synthesized.

The available NCO $\%$ was about $5.6 \mathrm{wt} \%$ for the intermediate compound $\mathrm{A}$, and its average molecular weight determined by end group analysis was about $1498.2 \pm 0.04$. The available $\mathrm{NCO} \%$ was about $1.8 \mathrm{wt} \%$ for the intermediate compound $\mathrm{B}$, and its average molecular weight established by end group analysis was about $2310.4 \pm 0.08$. These data show that the NCO functionality was about 2 and 1 for intermediate compounds A and B, respectively.

The average molecular weight of PA1 determined by end group analysis was about $2442.5 \pm 0.45$, and the available acid number established by titration method was about 46 . These data showed that the $\mathrm{COOH}$ functionality of PA1 was about 2. PA2 was synthesized through a procedure the same as PA1 except that we inserted two AS groups into the polymer structure as end-capping groups (Scheme S2). The same titration and calculation methods were conducted as above and the results showed that the $\mathrm{COOH}$ functionality of PA2 was about 4 (according to NCO titration test based on ASTM D 2572) [41].

In these two structures, HDI together with LAC have been incorporated in the hard segments of polymer chains whereas PEG has formed the soft parts.

Using aspartic acid (AS) as dispersing agent, we could prepare unique structures which can act as $\mathrm{pH}$-sensitive water dispersions. It means that PA1 and PA 2 could be dispersed in deionized water in the presence of $\mathrm{NaHCO}_{3}$ solution ( $\mathrm{pH}$ 8). Conversely, PA1-D and PA2-D dispersions were precipitated by addition of $\mathrm{HCl}(0.5 \mathrm{M})$ solution ( $\mathrm{pH} 6.5)$.

In this work, we used an amino acid, AS, as the internal dispersing agent that can be expectantly considered as a safe agent with respect to cytotoxicity. Thus, the AS end groups
Fig. $2{ }^{1} \mathrm{H}$ NMR (400 MHz) spectrum of PA1 in DMSO- $d_{6}$ at RT

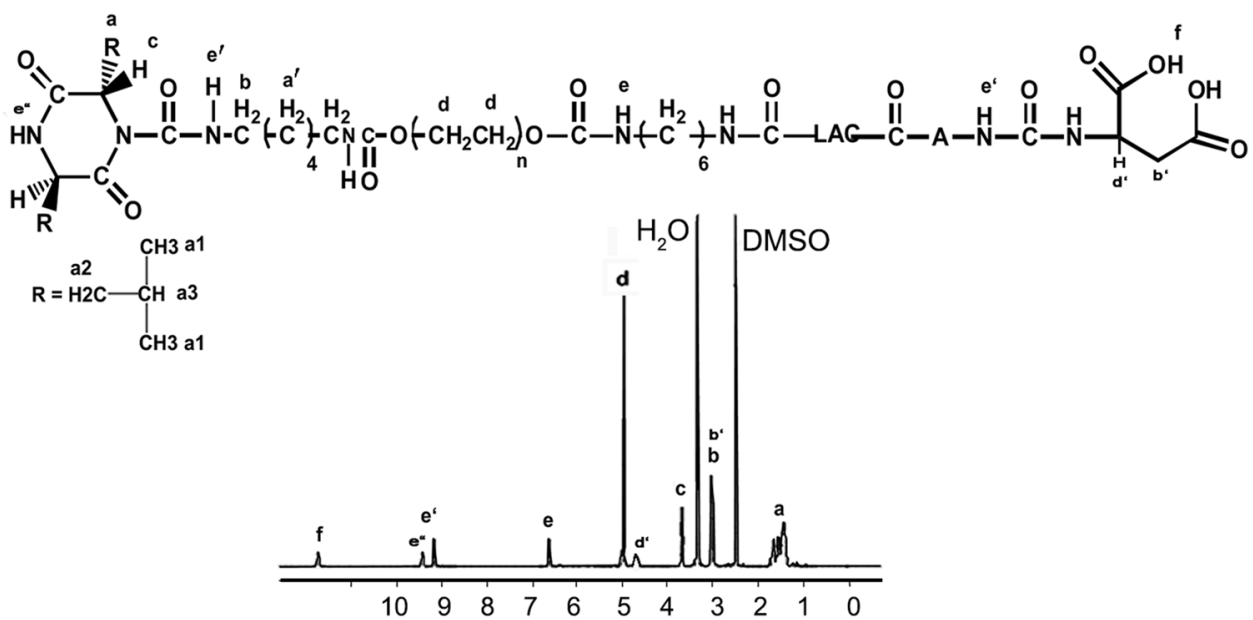


can serve as dispersing aids and the disperse-abilities of the polymers will depend on the $\mathrm{pH}$ values.

\section{Characterization}

The structures of PEUs were determined using FTIR and ${ }^{1}$ HNMR spectroscopy techniques. The FTIR spectra of the PEUs showed characteristic absorption bands of PEUs as expected. For instance, the FTIR spectrum of PA1 (Fig. 1) showed the $\mathrm{N}-\mathrm{H}$ characteristic absorption bands of amide, urea, urethane and acid groups around 3432, 3332, 3254, $3060 \mathrm{~cm}^{-1}$, respectively. The carbonyl groups $(\mathrm{C}=\mathrm{O})$ absorption bands of urethane, carboxylic acid, amide, and urea groups could be seen at 1772, 1721, 1676, and $1618 \mathrm{~cm}^{-1}$, respectively. The stretching vibration bands for the $\mathrm{C}-\mathrm{N}$ bonds in amide moieties represented two peaks at 1445 and $1363 \mathrm{~cm}^{-1}$. The band observed at $2925 \mathrm{~cm}^{-1}$ was related to the stretching vibration of aliphatic $\mathrm{C}-\mathrm{H}$, and the stretching band around $1255 \mathrm{~cm}^{-1}$ was correlated to $\mathrm{N}-\mathrm{COO}$ vibration. Ether $\mathrm{C}-\mathrm{O}-\mathrm{C}$ fragment showed two absorption bands around the 1070 and $945 \mathrm{~cm}^{-1}$. Therefore, based on these spectral proofs we confirmed the successful synthesis of PA1 and PA2.

${ }^{1} \mathrm{HNMR}$ peaks of PA1 in DMSO- $d_{6}$ at RT (Fig. 2) showed aliphatic hydrogen of LAC (a1-a3) and HDI (a') in the region of 1-2 ppm. The $\mathrm{CH}_{2}$ (b) protons of HDI moieties neighboring to $\mathrm{NH}$ are observed at $3 \mathrm{ppm}$. The chemical shifts of $\mathrm{CH}$ (c) belong to $\mathrm{LAC}$ and $\mathrm{CH}_{2}$ (d) of PEG appeared at $3.8 \mathrm{ppm}$ and $5.1 \mathrm{ppm}$, respectively. Urethane
$\mathrm{N}-\mathrm{H}(\mathrm{e})$ appeared around 6.5-6.9 ppm, and urea $\mathrm{N}-\mathrm{H}\left(\mathrm{e}^{\prime}\right)$ protons observed at 9.4-9.5 ppm. $\mathrm{CH}_{2}\left(\mathrm{~b}^{\prime}\right)$ and $\mathrm{CH}\left(\mathrm{d}^{\prime}\right)$ of AS appeared at about 3 and 4.8 ppm, respectively. Furthermore, we can see the chemical shift of acidic protons of AS at 11.4 ppm (Fig. 2).

\section{Particle size of dispersed PEUs}

The average particle sizes of dispersed PEUs (PA1-D and PA2-D) were determined by the Malvern Zetasizer instrument based on the Stokes-Einstein equation (Eq. (1)) as follows:

$d(H)=\frac{k T}{3 \pi \eta D}$,

where $k$ is Boltzmann's constant, $T$ is absolute temperature, $\eta$ is viscosity and $D$ is translational diffusion coefficient or velocity of brownian motion.

The results revealed that the particle size of dispersed PA1-D in water ( $\mathrm{pH} \mathrm{8)}$ was around $315.9 \mathrm{~nm}$ and that of dispersed PA2-D was approximately $400.7 \mathrm{~nm}$ (Table 1). Related reports about nano-sized carriers used in the drug delivery subjects suggest that the practical sizes of carriers should be less than $300 \mathrm{~nm}$. Then, they indeed pass the physiological barriers as the most effective factor which reduces the therapeutic effect of administering drug [42, 43]. Furthermore, it was demonstrated that in most tumors and infected tissues, large molecules ranging from 10 to $500 \mathrm{~nm}$

Table 1 Particle size and zeta potential data of PEUs

\begin{tabular}{|c|c|c|c|c|c|c|c|}
\hline $\begin{array}{c}\text { Polymer } \\
\text { code }^{\mathrm{a}}\end{array}$ & $\begin{array}{c}\mathrm{PEG}^{\mathrm{b}} \\
(\mathrm{mol} \%)\end{array}$ & $\begin{array}{c}\mathrm{AS}^{\mathrm{c}} \\
(\mathrm{mol} \%)\end{array}$ & $\begin{array}{c}\text { Hydrophobic } \\
\text { part }^{\mathrm{d}} \\
(\mathrm{mol} \%)\end{array}$ & Block structure $^{\mathrm{e}}$ & $\begin{array}{c}\eta_{\text {inh }}^{f} \\
(g / d L)\end{array}$ & $\begin{array}{c}\text { Potential }^{\mathrm{g}} \\
(\mathrm{mV})\end{array}$ & $\begin{array}{c}Z \text {-ave } \\
(\mathrm{nm})\end{array}$ \\
\hline PA1-D & 20 & 20 & 20 & & $0.40 \pm 0.1$ & $\begin{array}{c}-11.41 \pm \\
0.2\end{array}$ & $315.9 \pm 0.2$ \\
\hline PA2-D & 22.22 & 22.22 & 11.11 & & $0.42 \pm 0.1$ & $\begin{array}{c}- \\
11.80 \pm 0.30\end{array}$ & $400.7 \pm 0.5$ \\
\hline
\end{tabular}

${ }^{\text {a }}$ Polymers synthesized via A1 or A2 methods

${ }^{b}$ Percent of mole ratio of PEG to the total moles of monomers (as feed)

${ }^{c}$ Percent of mole ratio of As (aspartic acid) to the total moles of monomers (as feed)

${ }^{\mathrm{d}}$ Percent of mole ratio of LAC as Hydrophobic part to total moles of monomers (as feed)

${ }^{\mathrm{e}}$ Block structure in the polymer chain in which each component has represented by a graphical symbol ${ }^{-\ldots}$ PEG + HDI

${ }^{\mathrm{f}}$ Inherent viscosity. For measuring the inherent viscosity, $0.04 \mathrm{~g}$ of polymer was dissolved in $10 \mathrm{ml} \mathrm{DMF}$ and the flow time of polymer solution passing through a narrow capillary is compared to that of the pure solvent by Ostwald glass capillary (U-tube) viscometer

${ }^{g}$ Zeta potential of polymers measured by the Malvern Zetasizer instrument

${ }^{\mathrm{h}}$ Average of particle size of PA1-D and PA2-D measured by the Malvern Zetasizer instrument 
Scheme 3 Suggested PA1-D chains arrangements and their self-assembly in aqueous solution with $100 \%$ neutralization by $\mathrm{NaHCO}_{3}$
PEG+HDI

AS
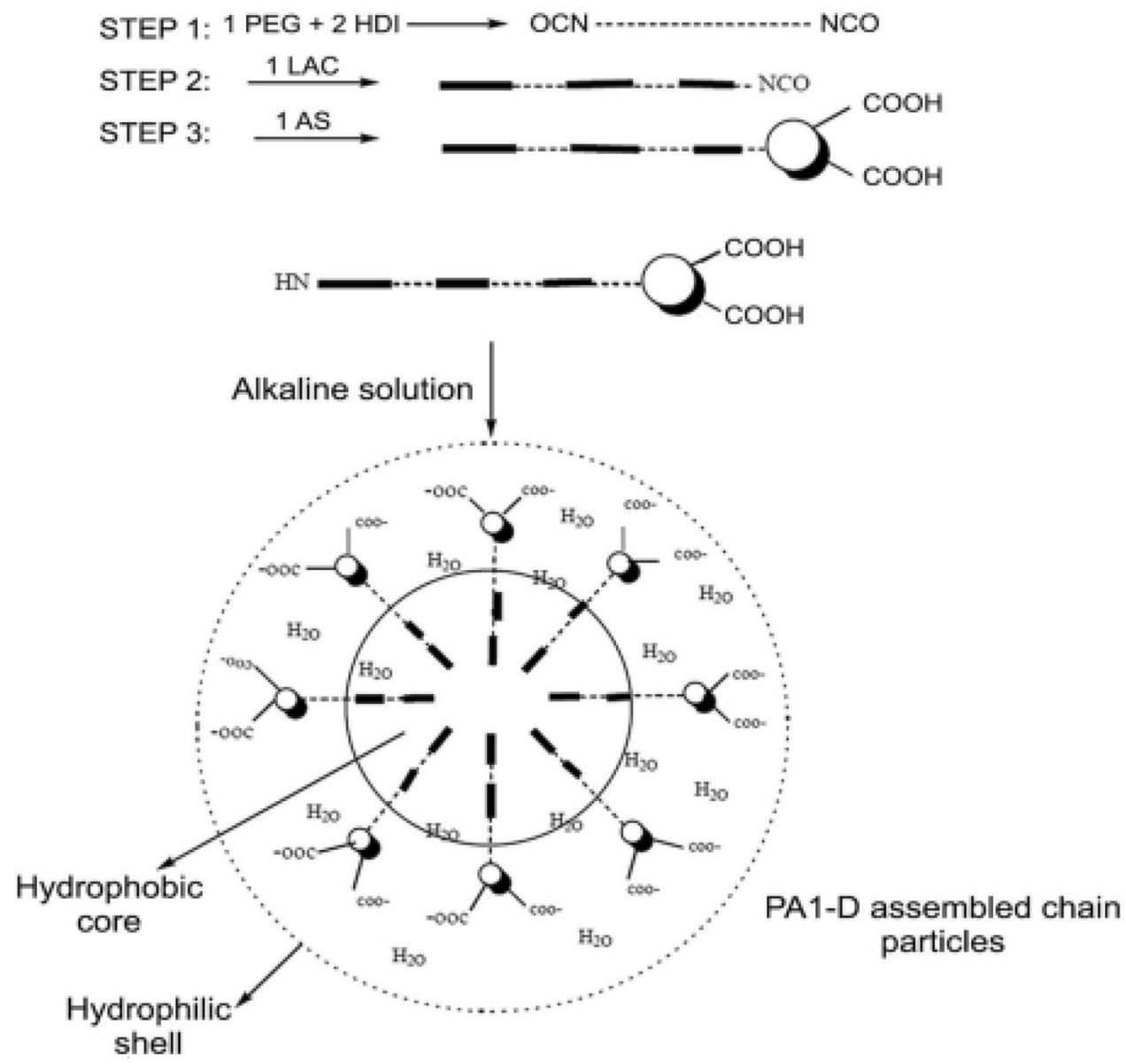

in size can leave the vascular bed and accumulate inside the interstitial space by EPR effect [44]. As a result, the sizes of these synthetic PEUs systems are in the acceptable applying range.

Schemes 3 and S3 suggest chain assemblies of PA1-D and PA2-D, respectively, where segments layouts were obtained based on the synthesis methods, order of addition of monomers, monomer ratios, and polymer end functionalities.

As shown in Table 1 and based on the schematic representations provided by scheme 3 and (Scheme S3), the particle size of PA2-D is a bit more than that of PA1-D, and this fundamentally can be related to the higher content of PEG in the PA2 chains which was a little more than that of PA1-D. Thus, when PA2-D is exposed to water, water molecules can diffuse into its chains because of grater hydrophilic parts in PA2-D and its hydrodynamic diameter increased compared to that of PA1-D [45-47]. In addition, the percentage of LAC as a hydrophobic segment in PA2 is lower than that of PA1. Thus, the presence of hydrophobic segments in PA1 chains prevents water diffusion and chain expansion which results in decrease of the sizes of PA1-D particles compared to that of PA2-D polymeric aggregates (Scheme 3).

It can be said that LAC monomers are located in the center of the PA2 chains. Therefore, in an aqueous environment, PA2-D chains fold so that they keep their hydrophobic parts away from water molecules (Scheme S3). In this way, the average size of PA2-D particles increases. In other words, hydrophobic LAC-HDI segments undergo intra-chain contraction and inter-chain association. The aggregated parts are quickly stabilized by hydrophilic PEG chains and AS ionic groups. PEU copolymers self-assemble into aggregates with hydrophobic LAC or LAC-HDI segments as the core and hydrophilic PEG segments and carboxyl groups as the corona. These results showed the effect of synthesis methods, the sequence of addition of monomers and monomers ratios on the polymer chain structures, surface zeta potentials, polymer chain aggregates, particle sizes, segments distributions along chains and water interaction behavior. These 
two completely different shaped polymeric scaffolds may be suitable as carriers in various drug delivery systems. They can interact with the hydrophilic and hydrophobic environments and drugs. Depending on the case, they would orient their hydrophilic or hydrophobic segments according to their surroundings.

\section{Zeta potential of dispersed PEUs nanoparticles}

The charge of each particulate system is the most critical factor which influences its applications. Therefore, we measured the surface zeta potentials of polymeric PA1-D and PA2-D samples. As we know, zeta potential is a scientific term used for electrokinetic potential. From a theoretical point of view, the zeta potential is the electric charge in the interfacial double layer (DL) at the slipping plane relative to a point in the bulk medium away from the interface. In other words, zeta potential is the potential difference between the dispersion medium and the stationary layer of fluid attached to the charged particles that move under an external applied electric field [45-47]. Zeta potential is calculated based on the following equation:

$\zeta=\frac{4 \pi \mu V}{E \varepsilon}$,

where $V$ is liquid migration speed, $\eta$ is the viscosity of the external environment, $E$ is voltage, $\varepsilon$ is dielectric constant of external environment, and $\zeta$ is zeta potential. The results are reported in Table 1 and zeta potential was found to be $-11.41 \mathrm{mV}$ for PA1-D and -11.80 for PA2-D.

Based on the results, these particulate systems have potential advantages for being used as the polymeric dispersed carriers. These values of ZP are enough and undoubtedly lead to thoroughly dispersed particles [48-50]. The negatively charged particles are not considered to agglomerate

Table 2 The results of degradation study of PEUs in PBS

\begin{tabular}{lll}
\hline Measured item & PA1 & PA2 \\
\hline Weight loss (\%) after 10 days $^{\mathrm{a}}$ & $23.24 \pm 0.50$ & $44.44 \pm 0.40$ \\
Primary viscosity & $0.40 \pm 0.02$ & $0.42 \pm 0.01$ \\
Viscosity decrement (\%) $^{\mathrm{b}}$ & 12.5 & 28.57 \\
Hydrophilic part (\%) PEG $^{\mathrm{c}}$ & 20 & 22.22 \\
Hydrophilic part (\%) aspartic acid $^{\mathrm{d}}$ & 20 & 22 \\
Hydrophobic part (\%) LAC $^{\mathrm{e}}$ & 20 & 11 \\
\hline
\end{tabular}

${ }^{a}$ Weight loss $(\%)=\frac{W 1-W 2}{w 1} \times 100$

${ }^{\mathrm{b}}$ Viscosity decrement $(\%)=\frac{v 1-v 2}{v 1} \times 100$

${ }^{\mathrm{c}}$ Percent of mole ratio of PEG relative to the total moles of monomers

${ }^{\mathrm{d}}$ Percent of mole ratio of As (aspartic acid) relative to the total moles of monomers

${ }^{\text {e }}$ Percent of mole ratio of LAC as hydrophobic part relative to the total moles of monomers during micelle formation [51, 52]. The ZP can be attributed to the particle size; that is, the larger the size of dispersed particle the more the speed of movement of surrounding liquid would be [45]. In addition, we measured the conductivity of solutions of PA1-D and PA2-D which were $44.2 \mathrm{mS} /$ $\mathrm{cm}$ and $49.3 \mathrm{mS} / \mathrm{cm}$, respectively. As expected, the surface potentials and conductivities would be increased with increasing the size of particles.

In the case of PA2-D, its particle size and percentage of AS residue are more than those of PA1 and PA1-D. Thus, the negative surface potential of PA2-D had increased compared to PA1-D. According to previous reports [45-47], the stability of a dispersed system depends on the level of zeta potential, molecular weight and particle size distribution. Since these two polymers, i.e., PA1 and PA2 almost had the same viscosities and PA2 had larger particle size, it was expected that PA2-D should have less stable particulate dispersions. However, due to its higher surface zeta potential and the higher number of acidic groups on its surface, PA2-D dispersion showed the same stability as PA1-D. Furthermore, both of the polymer dispersions possessed the excellent stability for more than 100 days.

\section{Degradation of PEUs in PBS solution}

Table 2 represents the results of degradation studies of PA1 and PA2 in PBS. Indeed, these degradation values are due to the extensive amount of biodegradable bonds that are present in peptide, urethane, amide and urea groups [53, 54].

The results in Table 2 indicated that the degradation rate of PA2 was more than that of PA1. It can be attributed to the higher amount of hydrophilic PEG participants in the PA2 chains. Degradation most probably started from the AS hydrophilic shell at the end of the polymer chains (Schemes 3 and S3). Since PA2 has two AS ending groups, then its degradation rate would be more than that of PA1. Briefly, it can be said that higher amount of hydrophilic parts and their accessibility (PEG and AS) and better diffusion of water molecules among the polymer chains resulted in the higher degradation rate of PA2 compared with that of PA1.

Other possibilities are the peptide bond dissociations in LAC rings and urea bonds dissociation at the connection of LAC to the polymer chains. However, it should be noted that these less hydrophilic parts of the chains are less exposed to water to take part in hydrolysis process considerably [55-57]. Furthermore, the LAC residue, due to its circular structure, needs to break through two bonds to afford the chain dissociation, and this would be more difficult to achieve (Scheme S4). In spite of these statements, comparing the control sample with PA2 showed that the presence of LAC moieties in the polymer backbone has a vital effect on the polymer biodegradation. The 
Fig. 3 FTIR spectra of PA1 sample before and after degradation in PBS solution for 10 days

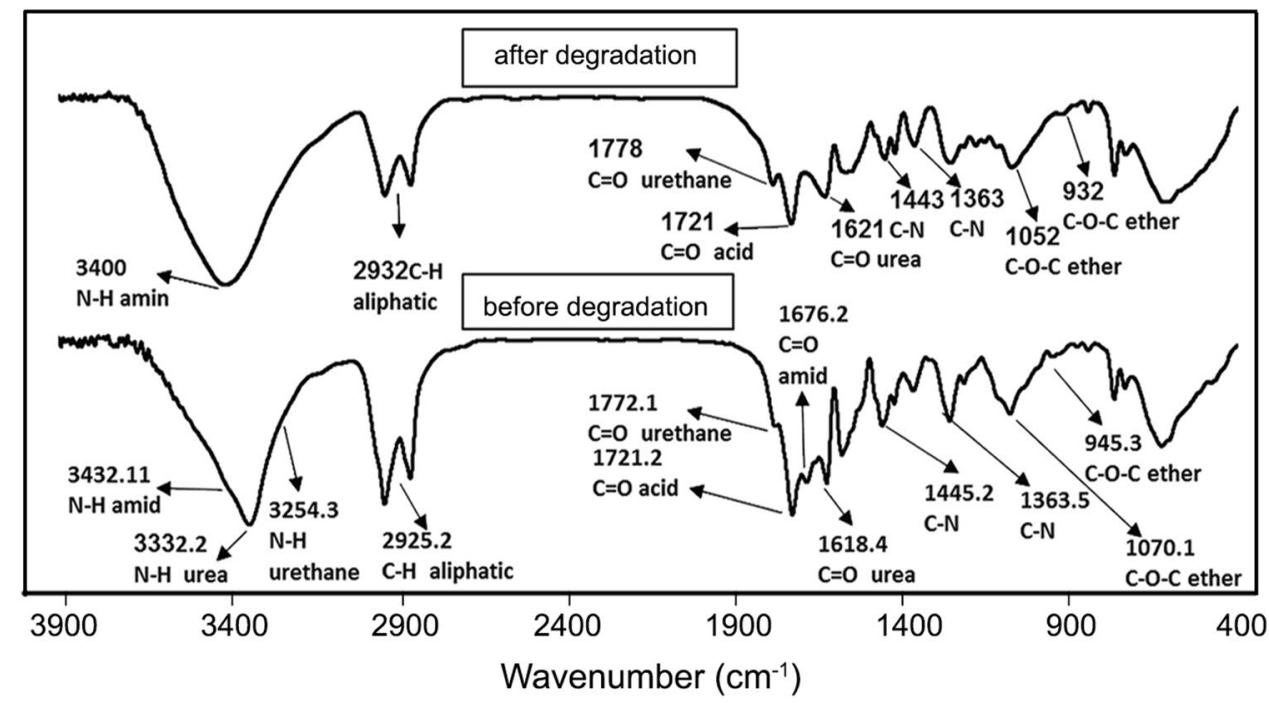

viscosity changes, in the same trends as weight changes for the two samples, confirmed the chain dissociations mentioned above (Table 2).

Degradation of each polymeric sample was further monitored through changes in their FTIR spectra before and after degradation tests. A substantial attention was paid for each sample, as well as for the blank, to eliminate possible errors due to non-homogeneity or thickness variations. The FTIR spectra showed that hydrolytic degradation occurs in PA1 and PA2 during PBS exposure. Figure 3 displays the polymers degradation and changes in functional groups using FTIR spectra. Dissociation of LAC residue in urea and peptide bonds produced secondary amine and free carboxylic acids groups. The disappearance
Fig. 4 AFM images of PA1 (a) before degradation in PBS; (b) after degradation in PBS
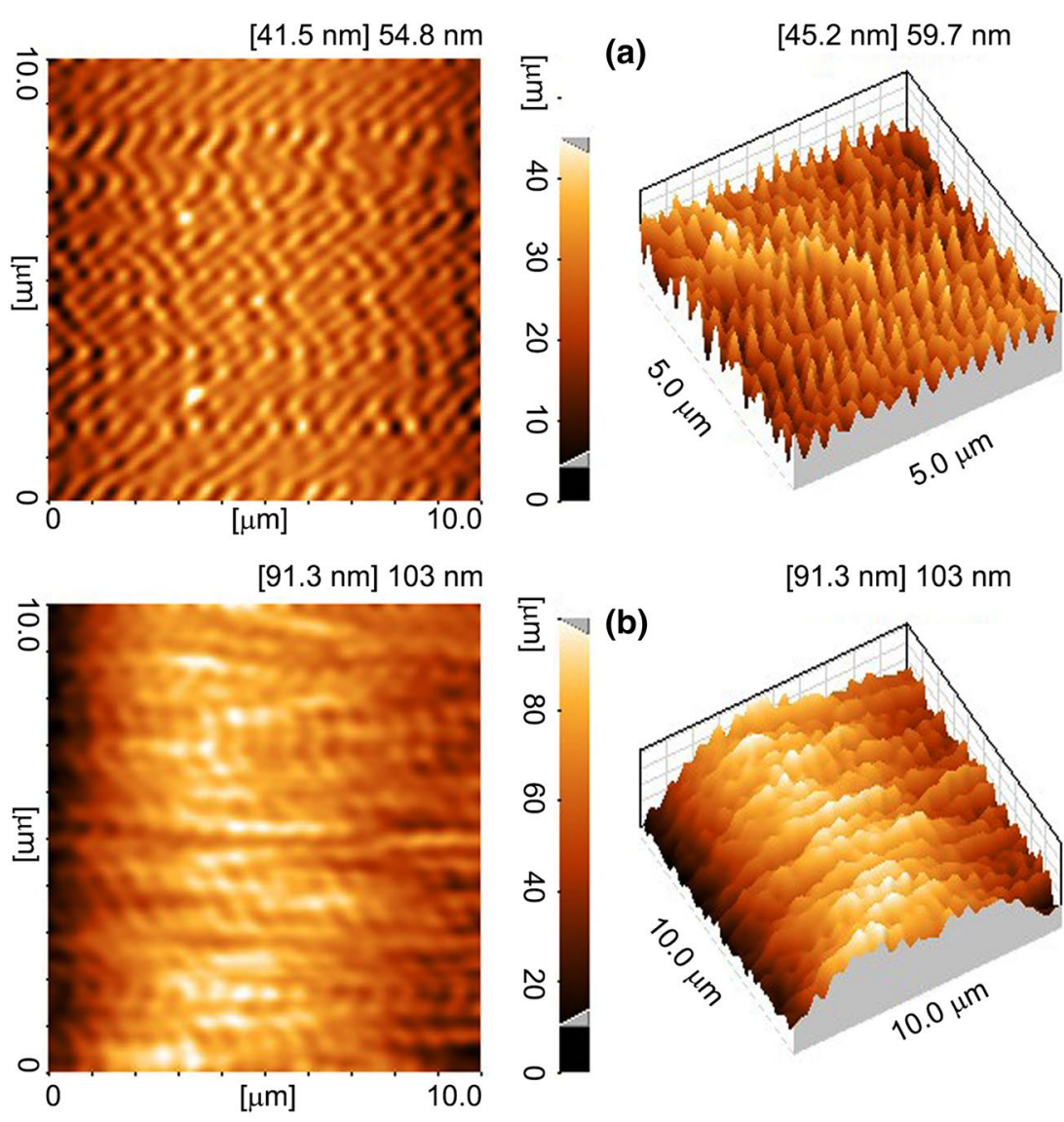

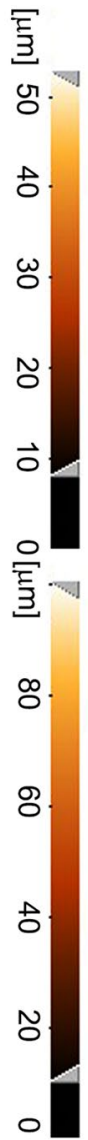


of carbonyl, $-(\mathrm{C}=\mathrm{O})-\mathrm{NH}$ - stretching band, belonging to the LAC peptide in FTIR spectrum after degradation confirmed this point (Scheme S4).

In addition, the absorption band of amide $\mathrm{N}-\mathrm{H}$ bond weakened, and the absorption band of the amine $\mathrm{N}-\mathrm{H}$ bond was appeared. In addition, during the hydrolysis process, some of the urethane bonds convert to alcohol and amic acid, which further were dissociated to amines and carbon dioxide. This process indeed is another reason for broadening of the $\mathrm{N}-\mathrm{H}$ peak in the FTIR spectrum. Other absorption bands related to urea linkages have also changed after degradation (Fig. 3). The spectral evidence for aspartic acid changes is apparent by reducing the $\mathrm{C}=\mathrm{O}$ band intensity of acid group of AS which can be related to the dissociation of AS end groups and polymer degradation. These results confirmed the deterioration of the polymer and supported the decrease in the weight and viscosity of the polymer.

\section{AFM}

Atomic force microscopy (AFM) has already been used to study the hydrolytic surface erosion of degradable polymers [58]. We used the AFM technique to study the hydrolytic surface degradation of PEUs in PBS solution, as well. From phase imaging, heterogeneity is evidenced by the two distinct regions, a region that appeared bright (hydrophilic region rich in PEG) and a region that is dark (hydrophobic region rich in LAC). The microstructure of PA1 film before exposure to PBS solution was found to be relatively smooth. Evident changes can be observed on the surface of PA1 film after exposure to the PBS solution (Fig. 4b). After the degradation period, the increase in the bright regions and surface roughness were apparent. This behavior can be due to the surface changes of the polymer as a result of water uptake and more hydrophilic nature of the polymer surface after degradation.

The striking point is due to non-uniform water uptaking, which was intensified in specific domains. This fact probably reveals the presence of micro-domains embedded in the bulk of polymer which contain more hydrophilic units. Based on these observations it is evident that water penetration started through more hydrophilic domains. After water penetration and hydrolytic degradation, in which urethane, urea, and peptide bonds were cleaved to amine, acid and alcohol moieties, and functional groups with higher hydrophilic character were produced; which resulted in the development of hydrophilic domains (bright regions). Thus, degradation may continue via additional water penetration. Consequently, hard segments or less hydrophilic domains with potential biodegradation may also be gradually involved and resulted in the development of hydrophilic domains and deterioration of hydrophobic domains (dark regions), as well.

\section{Cell cytotoxicity}

For initial cytotoxicity evaluation, L929 mouse fibroblast cells are well-proven cell lines, due to easy proliferation and adherence to the most of the biomaterial surface $[39,40]$. L929 cells were used in this study because they can be easily cultured in a reproducible way. The PEU sample was incubated with monolayer cells at $37^{\circ} \mathrm{C}$ for $24-48 \mathrm{~h}$. The PEU surface was studied using an optical microscope for surveying the cellular response after the specific incubation time. Cell cytotoxicity of the PEU sample was compared with a negative control (a nontoxic material: fibroblast cell culture) and a positive control (a toxic substance, i.e., stabilized PVC disk). The cell monolayer was examined microscopically for a response around the test sample.

The cell density on the negative control (Fig. 5a) is very similar to the fibroblast-like morphology with cell-to-cell contacts and filopodia extension. In contrast, the L929 cells are almost dead on the positive control (stabilized PVC disk) revealing severe toxicity (Fig. 5b). Similar to the negative control, the cells in contact with the PEU showed spindleshaped morphology characteristics of the mouse fibroblast cell line. The spindle-shaped L929 cells are found to adhere and expand on PEU (Fig. 5c). The cell adhesion studies after $48 \mathrm{~h}$, show that the cells have excellent adherence to the surface of PEU and the cell proliferation on polymer surface continued (Fig. 5d).

Furthermore, to evaluate the proliferation of the cells neighboring the polymer particles, we carried out an extra test in which we examined the medium of cells culture $48 \mathrm{~h}$ after removing the significant parts of the polymer; it clearly illustrates that the L929 cells have been able to continue their proliferation (Fig. 5e). Thus, the PEU sample has no considerable toxicity on the L929 cell line. The results suggest that the PEUs samples, PA1or PA2, may be considered as candidates for further biomedical studies.

\section{Functionalization of MWCNTs}

Recently, the attention to biomaterials containing nanofillers is rapidly increasing. In this study, MWCNTs were used as nano-fillers for biodegradable nontoxic PEUs, and for the first time, we prepared their mixed water dispersion composites. However, the primary limitation to this end was de-bundling and accumulation of MWCNTs in the polymer matrix owing to their first intramolecular Van der Waals forces and hydrophobic interactions. It has been shown that generating functional groups on CNTs surfaces successfully facilitates their interaction with the polymer matrix. One of the most usual chemical modification methods of CNTs is their surface modification to form oxygen-containing functional groups. The total oxygen content of MWCNTs by Boehm titration method was 0.01 and $1.3 \mathrm{mmol} / \mathrm{g}$ before and 

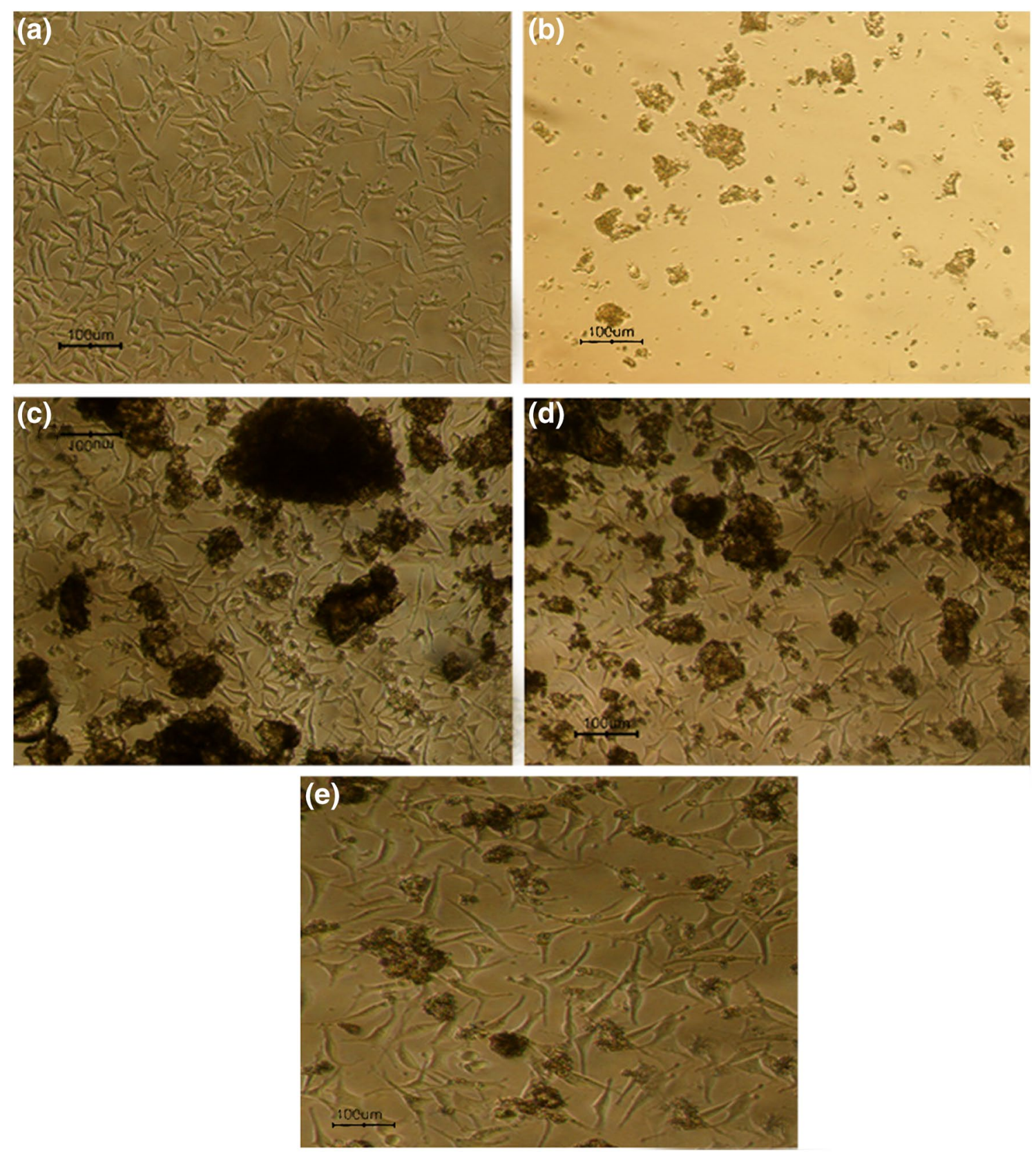

Fig. 5 L929 cells incubated with a negative control, b positive control, $\mathbf{c}$ PEU sample over $24 \mathrm{~h}, \mathbf{d}$ PEU sample over 48 h, e the medium of cells culture after removing the major parts of polymer after $48 \mathrm{~h}$

after treatment, respectively. In this work, due to the existence of AS moiety in the polymer structure, the MWCNTs were functionalized with aspartic acid (AS) as a bio-based molecule to improve interfacial interactions between the latter and former. Functionalization was done under microwave heating using a simple and low-cost method via formation of amide linkages between $\mathrm{COOHs}$ of MWCNTs and $\mathrm{NH}_{2}$ of AS (Scheme S5) [38, 39, 59].

\section{PEU/MWCNT-AS composites}

The PEUs containing different amounts of MWCNTsAS were fabricated using the casting solution method (Scheme 1). The carboxylic acid moieties initially presented on the surface of MWCNTs can interact with the functional groups of PEUs through hydrogen bonding interactions. 


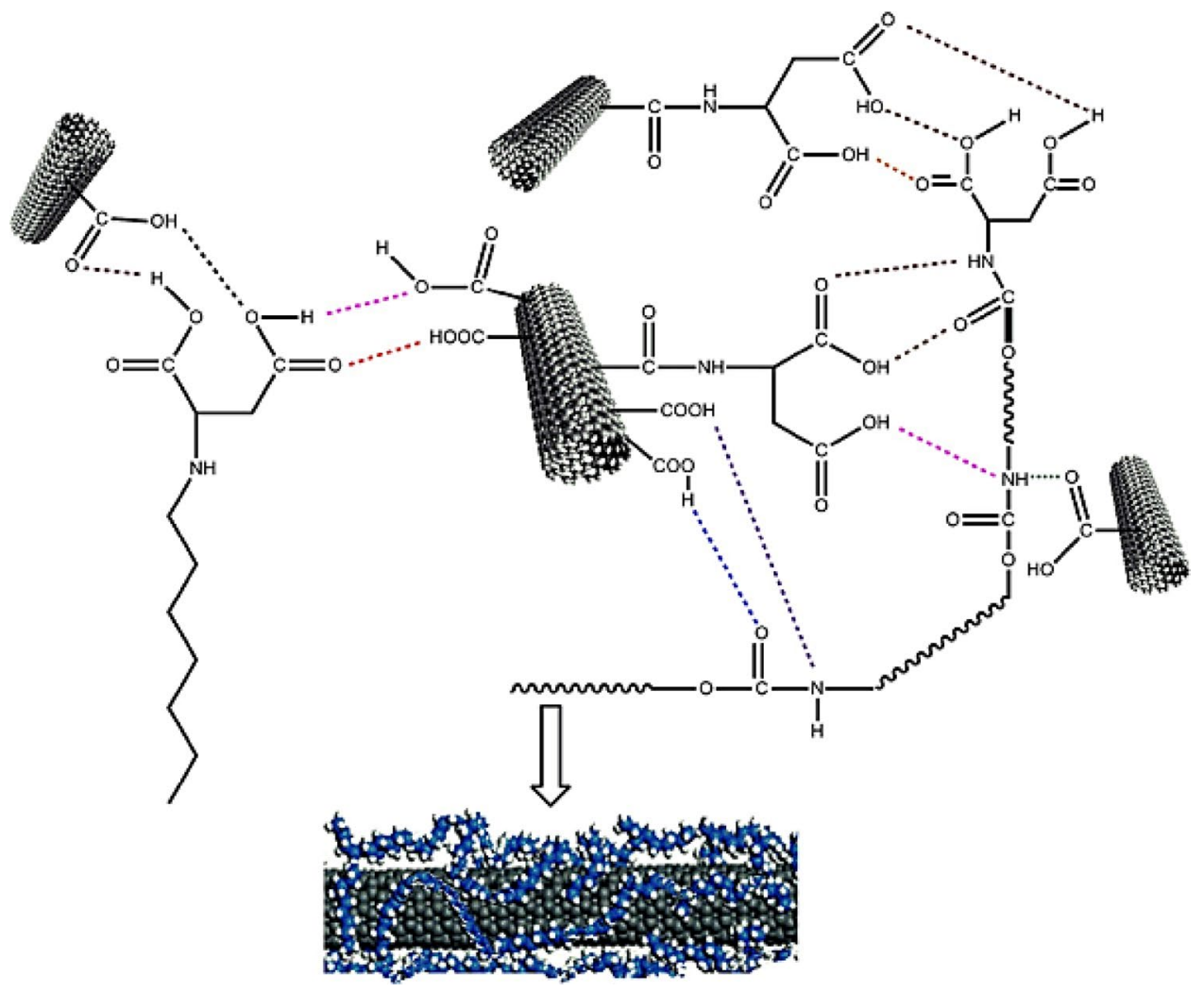

Scheme 4 All different possible hydrogen bonding interactions between functional groups of PEUs chains and functional groups of MWCNT-AS (urethane NH $---\mathrm{O}=\mathrm{C}$ aspartic acid on CNT or urethane $\mathrm{HN}---\mathrm{HO}$ aspartic acid on $\mathrm{CNT}$ or urethane $\mathrm{NH}---\mathrm{O}=\mathrm{C}$ carboxylic acid on $\mathrm{CNT}$ or urethane $\mathrm{HN}---\mathrm{HO}$ carboxylic acid on $\mathrm{CNT}$ or urethane $\mathrm{C}=\mathrm{O}---\mathrm{HO}$ aspartic acid on CNT or urethane $\mathrm{C}=\mathrm{O}---\mathrm{HO}$ carboxylic acid on $\mathrm{CNT}$ or polymer aspartic

Scheme 4 shows different possible hydrogen bonding interactions between functional groups of PEUs such as urethane $\mathrm{NH}$, urethane $\mathrm{C}=\mathrm{O}$, aspartic acid $\mathrm{OH}$ and aspartic acid $\mathrm{C}=\mathrm{O}$, and functional groups of MWCNTs-AS such as aspartic acid $\mathrm{OH}$, aspartic acid $\mathrm{C}=\mathrm{O}$ and $\mathrm{COOH}$ groups of MWCNTs. These interactions can affect thermal, dispersion and degradation properties of the polymers as well as water dispersion and polymer dispersion characteristics of MWCNTs.

\section{FTIR analysis of functionalized MWCNTs}

FTIR analysis confirmed the functionalization of MWCNTs. The FTIR spectra of the MWCNTs-OX and MWCNT-AS are shown in Fig S2 (a and b spectra). The presence of the intense and broad absorption band centered at $3425 \mathrm{~cm}^{-1}$, attributed to the $\mathrm{O}-\mathrm{H}$ stretching bands of carboxylic acid $(\mathrm{COOH})$ and hydroxyl $(\mathrm{OH})$ moieties attached to the surface of MWCNTs confirms the oxidization of MWCNTs (Fig. S2, spectrum a). The $\mathrm{C}-\mathrm{H}$ stretching band around acid $\mathrm{OH}---\mathrm{O}=\mathrm{C}$ aspartic acid on $\mathrm{CNT}$ or polymer aspartic acid $\mathrm{C}=\mathrm{O}---\mathrm{HO}$ aspartic acid on $\mathrm{CNT}$ or polymer aspartic acid $\mathrm{OH}$ $---\mathrm{O}=\mathrm{C}$ carboxylic acid on $\mathrm{CNT}$ or polymer aspartic acid $\mathrm{C}=\mathrm{O}--$ - HO carboxylic acid on CNT or polymer aspartic acid $\mathrm{HO}---\mathrm{HO}$ carboxylic acid on CNT) (This scheme DO NOT intend to show real polymer and CNT locations and interaction lay out. This only shows all different possible hydrogen bonding interactions)

$2919 \mathrm{~cm}^{-1}$, the $\mathrm{C}=\mathrm{O}$ stretching vibration of carboxylic acids at $1707 \mathrm{~cm}^{-1}$ and the $\mathrm{C}-\mathrm{O}$ stretching band of hydroxyl groups at $1165 \mathrm{~cm}^{-1}$ verify the oxidization of MWCNTs.

The spectrum of MWCNT-AS shows the appearance of two absorption bands at 1634 and $3438 \mathrm{~cm}^{-1}$ assigned to the amide $\mathrm{NH}$ and $\mathrm{C}=\mathrm{O}$, respectively. The modified MWCNTs were treated with $5 \mathrm{wt} \% \mathrm{HCl}$ solution to avoid aggregation and to get better dispersion. The presence of carboxylic acid and amidic $\mathrm{C}=\mathrm{O}$ stretching vibrations at 1710 and $1634 \mathrm{~cm}^{-1}$, respectively, confirmed the functionalization of MWCNTs with aspartic acid (Fig. S2, spectrum b).

\section{Morphology of functionalized MWCNTs and PEU/ MWCNTs-AS composites}

The microstructures of the MWCNT-OX and MWCNT-AS were studied by FESEM (Fig. 6). FESEM micrographs of pure PA1 and PA1/MWCNT-AS composite are shown the morphology and dispersity of MWCNTs-AS in the polymer matrix. The pure PEU showed spherical particles which 
Fig. 6 FE-SEM micrographs of the surface morphology of pure PEU (PA1) (a), PEU/MWCNTAS (b), MWCNTOX (c) and MWCNT-AS (d)
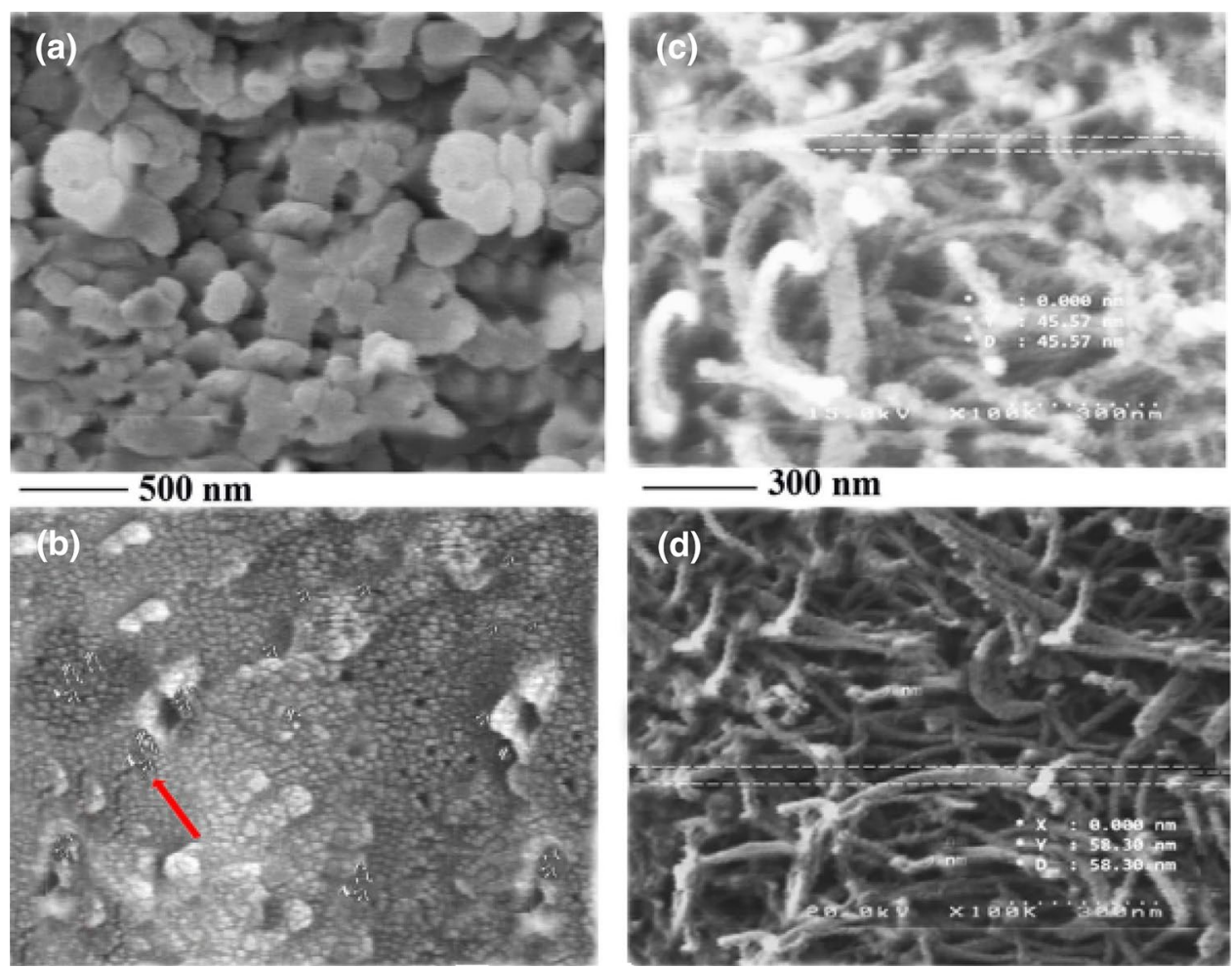

were self-arranged in nanoscale size (Fig. 6a). The average diameter of polymeric particles was about $300 \mathrm{~nm}$. PEU/ MWCNT-AS composite showed well dispersed and embedded nano-fillers in PEU matrix (Fig. 6b) where, particle size had reduced sharply and MWCNTs-OX showed a smooth surface (Fig. 6c). The surface of MWCNT-AS possessed an uneven and de-bundled structure (Fig. 6d).

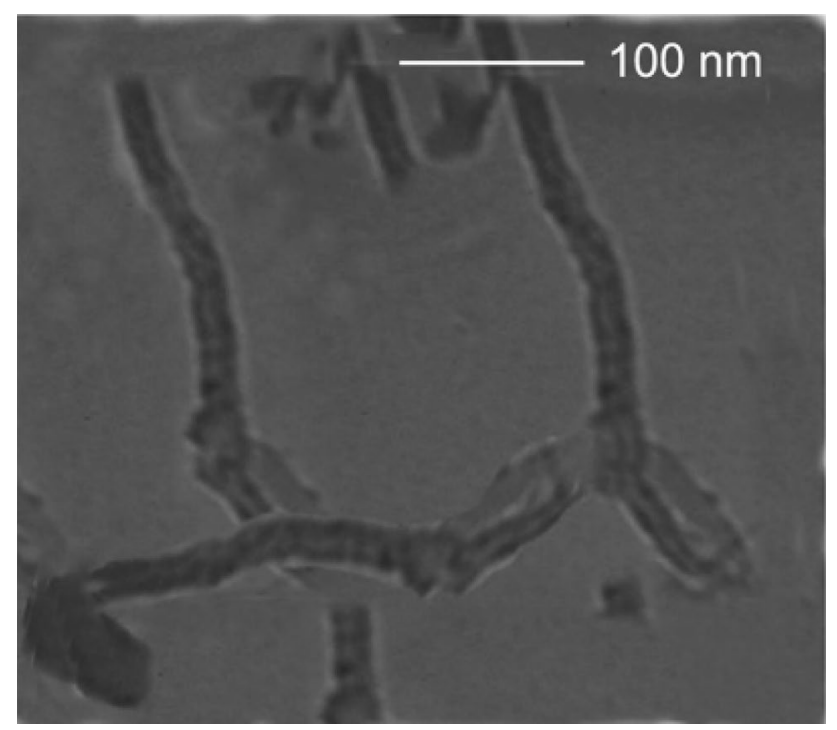

Fig. 7 TEM micrographs of PA1/MWCNT-AS (2 wt $\%$ ) composite sample
Comparison of the FESEM micrographs of pure PEU and PEU/MWCNT-AS composite (Fig. 6a, b) illustrated that the morphology of the polymer was changed after adding MWCNT-AS. According to FESEM micrograph (Fig. 6b), there are no MWCNTs migrated on the surface of

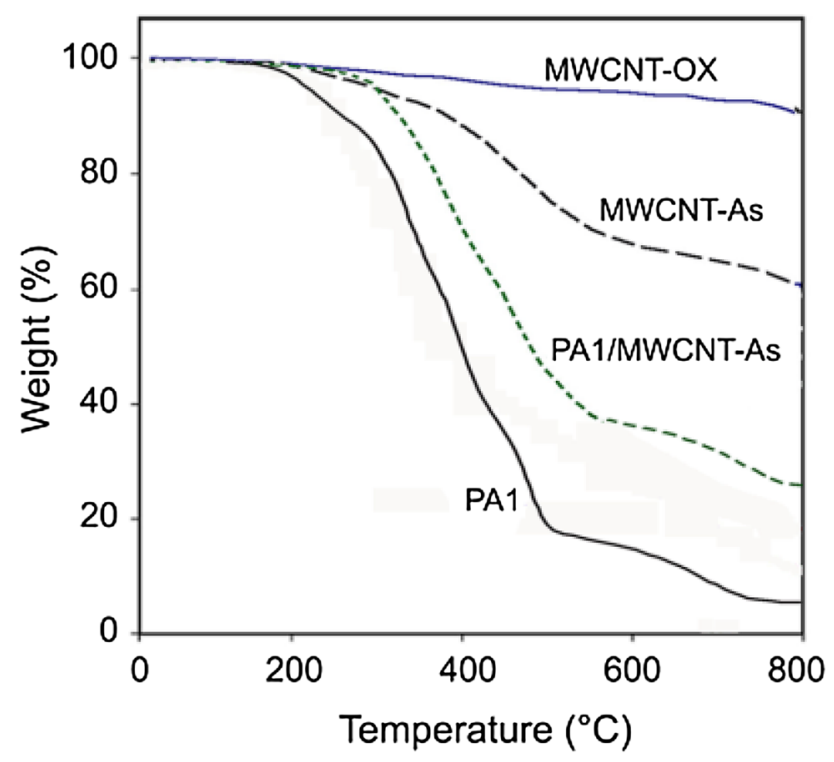

Fig. 8 TGA thermograms of MWCNT-OX, MWCNT-AS, pure PEU (PA1) and PA1/MWCNT-AS composite (2 wt $\%)$ 
Table 3 TGA data of MWCNT-OX, MWCNT-As, pure PEU (PA1) and PA1/ MWCNT-AS (2 wt \%) samples

\begin{tabular}{lllllll}
\hline Specimen & $T_{i}\left({ }^{\circ} \mathrm{C}\right)^{\mathrm{a}}$ & $T_{5 \%}\left({ }^{\circ} \mathrm{C}\right)^{\mathrm{b}}$ & $T_{10 \%}\left({ }^{\circ} \mathrm{C}\right)^{\mathrm{c}}$ & $\begin{array}{l}\text { Char } \\
\text { residue }^{\mathrm{d}} \\
(\%)\end{array}$ & LOI $(\%)^{\mathrm{e}}$ & $\Delta H_{\text {comb }}(\mathrm{J} / \mathrm{g})^{\mathrm{f}}$ \\
\hline MWCT-OX & 300 & 500 & $>800$ & $>90$ & 53.5 & 149.5 \\
MWCNT-AS & 227 & 300 & 395 & 60 & 41.5 & 192.7 \\
PEU (PA1) & 160 & 220 & 253 & 5 & 19.5 & 410.3 \\
PA1/MWCNT-AS & 226 & 306 & 340 & 26 & 27.9 & 286.7 \\
\hline
\end{tabular}

${ }^{\text {a }}$ Temperature at which initial weight loss was started at a heating rate of $10{ }^{\circ} \mathrm{C} / \mathrm{min}$ in nitrogen atmosphere

${ }^{\mathrm{b}}$ Temperature at which $5 \%$ weight loss was recorded at a heating rate of $10{ }^{\circ} \mathrm{C} / \mathrm{min}$ in nitrogen atmosphere

${ }^{\mathrm{c}}$ Temperature at which $10 \%$ weight loss was recorded at a heating rate of $10{ }^{\circ} \mathrm{C} / \mathrm{min}$ in a nitrogen atmosphere

${ }^{\mathrm{d}}$ Percentage weight of residue of material which left undecomposed after TGA analysis at maximum temperature $800{ }^{\circ} \mathrm{C}$ in nitrogen atmosphere

${ }^{\mathrm{e}}$ Limiting oxygen index (LOI) calculated at char residue at $800{ }^{\circ} \mathrm{C}$

${ }^{\mathrm{f}}$ Heat of combustion calculated from LOI the polymer; however, there are several holes and needle-like structures on the polymer surface that can show the existence of MWCNT-AS in the polymer matrix and also the wrapping of MWCNTs-AS by polymer chains through different ways of interactions between functional groups of modified MWCNTs and PEU chains. It is clear that covalent bonding, Van der Waals interactions and hydrogen bonding between $\mathrm{COOH}, \mathrm{OH}, \mathrm{NH}$ and $\mathrm{C}=\mathrm{O}$ groups on the surface and edges of MWCNTs-AS, and the amide, urethane, urea and acid functional groups of polymer chains were responsible for these phenomena. Furthermore, $\pi-\pi$ interactions between MWCNTs-AS caused more connections. all of these factors caused the polymer to wrap around MWCNTs and also made changes in the polymer morphology (Scheme 4).

Figure 7 shows the TEM image of the functionalized MWCNTs dispersed in the PA1 matrix. It can be seen that the interfacial interactions between the MWCNT-AS and the PEU matrix play an important role in improving the dispersion of MWCNTs in the PEU matrix and the polymer composite properties. The interactions between several organic functional groups especially $\mathrm{OH}, \mathrm{NH}$, and $\mathrm{C}=\mathrm{O}$ groups, lead to the better interaction of the PEU chains with MWCNTAS and mutually better dispersion of MWCNTs-AS in the PA1 matrix.

\section{TGA}

Figure 8 shows the TGA curves of pure PA1, modified MWCNTs samples and PA1/MWCNT-AS composite. The data obtained from these studies are presented in Table 3 . The major single step degradation was observed for all the samples.

The TGA curve of oxidized CNTs showed a small mass loss starting at $300{ }^{\circ} \mathrm{C}$. The weight loss of MWCNTs functionalized with AS started at $227^{\circ} \mathrm{C}$ resulted from the decomposition of the organic functional groups attached to the MWCNTs.

TGA data of the modified MWCNTs suggests that the MWCNTs can resist in thermo-degradation temperatures up to $800{ }^{\circ} \mathrm{C}$. The temperature at which $5 \%$ weight loss was recorded for MWCNTs-OX was about $500{ }^{\circ} \mathrm{C}$, indicating that the MWCNTs-COOH were thermally stable up to this temperature, while the AS functionalized MWCNTs slowly lost $5 \%$ of their weight at about $300{ }^{\circ} \mathrm{C}$ owing to losing organic functional groups. Thus, it can be concluded that the thermal stability of MWCNTs-OX has reduced after its functionalization with AS.

Comparing TGA curves of pure PEU with PEU/ MWCNT-AS composite, it can be seen that the thermal stability of the PEU/MWCNT-AS composite has been increased. This can be due to the higher thermal stability and thermal conductivity of MWCNTs that facilitate heat dissipation within the polymer nanocomposites. Therefore, this thermal conductivity prevents the accumulation of heat at specific points within the polymer matrix for degradation. This property can induce sterilization ability of the polymer for medical purposes. The weight residue after significant degradation at $800{ }^{\circ} \mathrm{C}$ for PEU/MWCNT-AS composite was higher than that of pure PEU as well. Limiting oxygen indexes (LOI) of PEU and PEU/MWCNT-AS composite and their heat of combustion were calculated upon their respective char residues at $800{ }^{\circ} \mathrm{C}$ according to Eqs. (3) and (4). It is said that a material with $21 \%<\mathrm{LOI}<28 \%$ is considered as a "slow-burning" material. A material with LOI higher than $28 \%$ would be considered as a "self-extinguishing" material. Thus, PEU and PEU/MWCNT-AS composite can be considered as relatively "slow-burning" materials.

According to Van Krevelen [60] and Johnson [61] for halogen-free polymers, two theoretical relationships exist between the LOI and the parameters of the combustion process: char residue $(\mathrm{CR})$ and heat of combustion $\left(\Delta H_{\text {comb }}\right)$. 
Table 4 Particle size and zeta potential data of dispersed composite PEUs/MWCNTAS-D

\begin{tabular}{lll}
\hline Dispersed composite & Potential $(\mathrm{mV})^{\mathrm{a}}$ & $Z$-avg $(\mathrm{nm})^{\mathrm{d}}$ \\
\hline PA1/MWCNT-As-D & $-22.5 \pm 0.1^{\mathrm{b}},-18.5 \pm 0.1^{\mathrm{c}}$ & $200 \pm 0.1^{\mathrm{e}}, 100 \pm 0.12^{\mathrm{f}}, 50 \pm 0.11^{\mathrm{g}}$ \\
PA2/MWCNT-As-D & $-23.82 \pm 0.1^{\mathrm{b}},-18.8 \pm 0.1^{\mathrm{c}}$ & $320 \pm 0.22^{\mathrm{e}}, 160 \pm 0.14^{\mathrm{f}}, 85 \pm 0.21^{\mathrm{g}}$ \\
\hline
\end{tabular}

${ }^{a}$ Zeta potential of dispersed composite (with $0.5^{\mathrm{b}}$ and $2^{\mathrm{c}} \mathrm{wt} \%$ MWCNT-As percentage content; ${ }^{\mathrm{d}}$ the average of particle size of dispersed composite (with $0.5^{\mathrm{e}}, 1^{\mathrm{f}}$, and $2^{\mathrm{g}} \mathrm{wt} \%$ MWCNT-As percentage content)
From these equations, the higher the char residue of a material, the better will be its flame retardant property.

LOI $=17.5+0.4 \mathrm{CR}$

LOI $=8000 / \Delta H_{\text {comb }}$,

where $\Delta H_{\text {comb }}$ is the specific heat of combustion in $\mathrm{J} / \mathrm{g}$.

PA1 showed a minor thermal degradation of about $13 \%$ weight loss between 160 and $293{ }^{\circ} \mathrm{C}$ in step 1 . It showed its major thermal degradation of about $68 \%$ between 293 and $513{ }^{\circ} \mathrm{C}$ and immediately after that it showed another $13 \%$ weight loss between 513 and $800^{\circ} \mathrm{C}$. The PA1/MWCNT-AS composite showed its major thermal degradation of about $63 \%$ between 226 and $566{ }^{\circ} \mathrm{C}$ and immediately after that it showed another $11 \%$ weight loss between 566 and $800{ }^{\circ} \mathrm{C}$.

\section{Dispersion properties of PEU/MWCNT-AS-D}

We analyzed the particle sizes of dispersed composites, PA1/ MWCNT-AS-D and PA2/MWCNT-AS-D, with different contents of MWCNT-AS by the Zetasizer instrument. The results show that the particle sizes of dispersed composites in water ( $\mathrm{pH} \mathrm{8)}$ were in the range of $50-200 \mathrm{~nm}$ for PA1/ MWCNT-AS-Ds and the particle sizes of dispersed PA2/ MWCNT-AS-Ds were in the range of 85-320 nm (Table 4).

In addition, the zeta potentials of dispersed composite samples were measured in this study. Zeta potentials were calculated based on the Eq. (2). The results are reported in Table 4 and found to be $-22.5 \mathrm{mV}$ for PA1/ MWCNTAS( $0.5 \%)$-D and $-23.82 \mathrm{mV}$ for PA2/MWCNT-AS (0.5\%)D. The negatively charged particles do not agglomerate during particles dispersion.

As previously mentioned, the stability of a dispersed system depends on its level of zeta potential, molecular weight and particle size distribution. It can be seen that the particle sizes of composites have decreased with increasing the nano-filler content in comparison with the particle size of the pure PEU dispersion. On the other hand, the zeta potentials of the dispersed particles with increasing filler content have decreased. As mentioned before, the surface potential will increase with increasing the size of particles. However, despite decrease in the surface potentials of the dispersed particles compared with that of pure PEU, they have longer dispersion stabilities (for more than 100 days); this is because of their higher ratios of surface zeta potentials to smaller particle size (higher charge density) and the presence of more acidic groups on their surface compared with pure PEU (Scheme S6).

\section{Degradation of PEUs/ MWCNT-AS composites in PBS solution}

The hydrolytic degradations of PA1/ MWCNT-AS (2\%) and PA2/ MWCNT-AS (2\%) polymer composites were studied in PBS solution (pH 7.4) at $37^{\circ} \mathrm{C}$ and were compared with those of PA1 and PA2. The results showed that the percentages of weight losses of the two composites samples were lesser than those of PA1 and PA2, respectively. The weight loss percentages of PA1/MWCNT-AS (2\%) and PA2/MWCNT-AS (2\%) were $19 \%$ and 39.5\%, respectively. It can be said that the inclusion of carbon nano-fillers into the PEU matrix, due to their strong SP2 carbon-carbon bonding and their geometric arrangement, has enhanced the strength of the polymer matrix. Lower degradation of composite samples compared with pure polymer samples can be due to more interchain interactions of the composites relative to pure polymers. Due to the interaction of several functional groups of the PEU chains with functional groups of MWCNTs-AS, it can be expected that the chain packing distances of the polymer on MWCNTs decreases, leading to better interactions of the PEU chains with MWCNTsAS. These compacted interactions between PEU chains and MWCNTs-AS decreased the insertion of water molecules into the PEU-PEU and PEU-MWCNT-AS chains spaces (Scheme S7).

In addition, water uptake study of polymers and composites showed that composites incorporating MWCNTs, are more hydrophobic compare with the polymers. Thus, it can be said that hydrophobic effect of MWCNTs can play a role on reduction of degradation of PEUs/MWCNT-AS composites. The maximum water uptake of PA1, PA2 and PA1/ MWCNT-AS were occurred after 11,13 and $18 \mathrm{~h}$, respectively. Their maximum water-uptakes were 600,775 and $437 \%$, respectively. Their equilibrium water uptakes after $72 \mathrm{~h}$ were 387, 437 and 225\%, respectively (Fig S3). 


\section{Conclusion}

PUs have good physicochemical properties, which make them appropriate candidates for biomedical applications especially in drug delivery systems. Moreover, to make PUs as bio-friendly systems, designing water based PUs with biofriendly monomers can be a promising strategy. Embedding functionalized CNTs (f-CNT) into polymer matrices which leads to a good distribution of f-CNTs is expected to develop new potential applications in diverse fields. Recently, CNTs have been raised as excellent nano-carriers for the highly efficient delivery of drugs and biomolecules. Thus, in this study for the first time, two different newly designed waterdispersed polymers and dispersed CNT nano-composites were prepared. The dispersed nano-composites were prepared via the simultaneous dispersion of functionalized MWCNTs and new PEUs. The PEUs based on PEG-1000 and amino acids were successfully synthesized by the reaction of NCO-terminated oligo-ether urethanes consisting of HDI-PEG as hydrophilic soft segments with LAC as the peptide-based chain extender. Hydrophobic hard segments were originated from the reaction of an amino acid-based monomer, LAC, with HDI. The polymerization reactions were performed in NMP as a solvent in the absence of any catalyst. Notably in this work Aspartic acid (AS) was successfully used for end functionalization of polymer chains and MWCNTs' surfaces as a bio-friendly dispersing agent.

Our comprehensive studies show that synthesis methods, the sequence of addition of monomers and monomers ratios have influences on the polymer chain structures, surface zeta potentials, water penetration into particles and degradation rates, particle sizes and hydrophilic/hydrophobic segments distributions along the polymer chains. Thus, it is possible to design completely different shaped polymeric scaffolds with different degradation and dispersion properties. The degradation study of polymers in PBS solution suggested the idea that the degradation is a hydrolysis process and after 10 days of immersion, the weight losses were about $23.24 \%$ (PA1) and $44.44 \%$ (PA2). PA1 and PA2 showed no toxicity with L929 fibroblast cell line. In addition, in this study, functionalized MWCNTs-AS under microwave irradiation were prepared as fast and economic route. Then polymer/MWCNTAS composites and polymer/MWCNT-AS water dispersion composites were manufactured. Interestingly, it was shown that the degradation rate of polymers and the size of waterdispersed-composites aggregates decreased with increasing MWCNT-AS loading. It can be seen that PEU/MWCNT-AS composites show improved dispersion of MWCNTs-AS in the PEU matrix, increased thermal stability and enhanced water dispersion stabilities for more than 100 days. It can be said that the inclusion of carbon nano-fillers into PEU matrix has enhanced the strength of the polymer matrix, owing to the interactions of several functional groups of the PEU chains with functional groups of MWCNTs-AS. This improved feature has reduced degradation of each composite sample compared with pure polymer samples. Compacted interaction between PEU chains and MWCNT-AS as well as hydrophobic effect of CNTs decreased the insertion of water molecules into the PEU-PEU and PEU-MWCNT-AS chains spaces which results in lower degradation rates and reduced particle sizes.

This study showed that MWCNTs-AS have affected thermal, degradation and dispersion properties of PEUs. Furthermore, interaction of polymer chains on the surface of MWCNTs improved water disperse-ability of CNTs. Our primary studies showed that these dispersed polymers and their PEU/MWCNT-As composites dispersions show tunable properties such as surface zeta potentials, water absorptions, degradation rates and particle sizes which make them appropriate candidates as potential drug carriers.

Acknowledgements This project was supported by University of Isfahan and Isfahan University of Medical Sciences (Grant no: 295190).

\section{References}

1. Lamba NMK, Woodhouse KA, Cooper SL (1997) Polyurethanes in biomedical applications. CRC press, Boca Raton

2. Zdrahala R, Zdrahala IJ (1999) Biomedical applications of polyurethanes: a review of past promises, present realities, and a vibrant future. J BiomaterAppl 14:67-90

3. Ulery BD, Nair LS, Laurencin CT (2011) Biomedical applications of biodegradable polymers. J Polym Sci B Polym Phys 49:832-864

4. Batyrbekov Y, Iskakov R (2012) Polyurethane as carriers of antituberculosis drugs/polyurethane. In: Tech Publish, pp 147-170

5. Mishra A, Singh SK, Dash D, Aswal VK, Maiti B, Misra M, Maiti P (2014) Self-assembled aliphatic chain extended polyurethane nanobiohybrids: emerging hemocompatible biomaterials for sustained drug delivery. Acta Biomater 10:2133-2146

6. Cakic SM, Stamenkovic JV, Djordjevic DM, Ristic IS (2009) Synthesis and degradation profile of cast films of PPG-DMPA-IPDI aqueous polyurethane dispersions based on selective catalyst. Polym Degrad Stab 94:2015-2022

7. Zhou L, Liang D, He X, Li J, Tan H, Li J, Fu Q, Gu Q (2012) The degradation and biocompatibility of $\mathrm{pH}$-sensitive biodegradable polyurethanes for intracellular multifunctional antitumor drug delivery. Biomaterials 33:2734-2745

8. Chiono V, Sartori S, Calzone S, Boffito M, Tonda-Turo C, Mattu C, Gentile P, Ciardelli G (2017) In: Zhang X (ed) Science and principles of biodegradable and bioresorbable medical polymers, 1st edn. Elsevier, Amsterdam, Part one, Chapter 6

9. Zhang J, Wu M, Yang J, Wu Q, Jin Z (2009) Anionic poly(lactic acid)-polyurethane micelles as potential biodegradable drug delivery carriers. Colloids Surf A 337:200-204

10. Reddy TT, Kano A, Maruyama A, Takahara A (2010) Synthesis, characterization and drug release of biocompatible/biodegradable non-toxic poly(urethaneurea)s based on poly( $\varepsilon$-caprolactone) $\mathrm{s}$ and lysine-based diisocyanate. J Biomater Sci Polym Ed 21:1483-1502 
11. Zhou L, Yu L, Ding M, Li J, Tan H, Wang Z, Fu Q (2011) Synthesis and characterization of $\mathrm{pH}$-sensitive biodegradable polyurethane for potential drug delivery applications. Macromolecules 44:857-864

12. Jiang X, Li J, Ding M, Tan H, Ling Q, Zhong Y, Fu Q (2007) Synthesis and degradation of nontoxic biodegradable waterborne polyurethanes elastomer with poly( $\varepsilon$-caprolactone) and poly(ethylene glycol) as soft segment. Eur Polym J 43:1838-1846

13. Kim BK, Lee JC (1996) Waterborne polyurethanes and their properties. J Polym Sci A Polym Chem 34:1095-1104

14. Zhang C, Wen X, Vyavahare NR, Boland T (2008) Synthesis and characterization of biodegradable elastomeric polyurethane scaffolds fabricated by the ink jet technique. Biomaterials 29:3781-3791

15. Rafiemanzelat F, Zonouz AF, Emtiazi G (2013) Synthesis of new poly(ether-urethane-urea)s based on amino acid cyclopeptide and PEG: study of their environmental degradation. Amino Acids 44:449-459

16. Masayuki Y, Kwon GS, Teruo O, Yasuhisa S, Mayumi N, Kazunori K (1994) Influencing factors on in vitro micelle stability of adriamycin-block copolymer conjugates. J Control Release 28:59-65

17. Marcos-Fernández A, Abraham GE, Valentin JL, San Román J (2006) Synthesis and characterization of biodegradable non-toxic poly(ester-urethane-urea)s based on poly( $\varepsilon$-caprolactone) and amino acid derivatives. Polymer 43:785-798

18. Jiang X, Yu F, Wang Z, Li J, Tan H, Ding M, Fu Q (2010) Fabrication and characterization of waterborne biodegradable polyurethanes 3-dimensional porous scaffolds for vascular tissue engineering. J Biomater Sci Polym Ed 21:1637-1652

19. Kääriä K, Hirvonen A, Norppa H, Piirilä $P$, Vainio H, Rosenberg C (2001) Exposure to 4,4'-methylenediphenyl diisocyanate (MDI) during moulding of rigid polyurethane foam: determination of airborne MDI and urinary 4,4'-methylenedianiline (MDA). Analyst 126:476-479

20. Cherng JY, Hou TY, Shih MF, Talsma H, Hennink WE (2013) Polyurethane-based drug delivery systems. Int J Pharm 450:145-162

21. Khan W, Muthupandian S, Farah S, Kumar N, Domb AJ (2011) Biodegradable polymers derived from amino acids. Macromol Biosci 11:1625-1636

22. Long DD, Tennant-Eyles RJ, Estevez JC, Wormald MR, Dwek RA, Smith MD, Fleet GWJ (2001) Carbopeptoids: peptides and diketopiperazines incorporating the anomeric centre of mannopyranose. J Chem Soc Perkin Trans 1:807-813. https://doi. org/10.1039/B009940F

23. Einholm AP, Pedersen KE, Wind T, Kulig P, Overgaard MT, Jensen JK, Bødker JS, Christensen A, Charlton P, Andreasen PA (2003) Biochemical mechanism of action of a diketopiperazineinactivator of plasminogen activator inhibitor-1. Biochem J 373:723-732

24. Nicholson B, Lloyd GK, Miller BR, Palladino MA, Kiso Y, Hayashi Y, Neuteboom ST (2006) NPI-2358 is a tubulin-depolymerizing agent: in-vitro evidence for activity as a tumor vascular-disrupting agent. Anticancer Drug 17:25-31

25. Houston DR, Synstad B, Eijsink VGH, Stark MJR, Eggleston IM, Van Aalten DMF (2004) Structure-based exploration of cyclic dipeptide chitinase inhibitors. J Med Chem 47:5713-5720

26. Song JW, Kim CZ, Han JW, Kim MS, Hwang SK (2003) Improvement in mechanical properties of magnesium alloy (AZ31) sheet fabricated by casting and subsequent plastic working. Exp Biol Med 228:1338-1345 (Mater Sci Forum 439:227-232)

27. Wyatt PG, Allen MJ, Borthwick AD, Davies DE, Exall AM, Hatley RJD, Irving WR, Livermore DG, Miller ND, Nerozzi F, Sollis SL, Szardenings AK (2005) 2,5-Diketopiperazines as potent and selective oxytocinantagonistse1: identification, stereochemistry and initial SAR. Bioorg Med Chem Lett 15:2579-2582
28. Wang D-X, Liang M-T, Tian G-J, Lin H, Liu H-Q (2002) A facile pathway to synthesize diketopiperazine derivatives. Tetrahedron Lett 43:865-867

29. Martins MB, Carvalho I (2007) Diketopiperazines: biological activity and synthesis. Tetrahedron 63:9923-9932

30. Matthews SE, Pouton CW, Threadgill MD (2000) A biodegradable multiblock co-polymer derived from an alpha, omega-bis (methylamino) peptide and an alpha, omega-bis(oxiranylmethyl) poly(ethylene glycol). J Control Release 67:129-139

31. Rafiemanzelat F, Abdollahi E (2010) Synthesis and characterization of hydrolysable poly(ether-urethane-urea)s derived from $L$-leucine anhydride cyclopeptide; a green synthetic method for monomer. Polym Degrad Stab 95:901-911

32. Zhang M, Yudasaka M (2014) Potential application of nanocarbons as a drug delivery system. Carbon 69:642-655

33. Zhang W, Zhang Z, Zhang Y (2011) The application of carbon nanotubes in target drug delivery systems for cancer therapies. Nanoscale Res Lett 6:555-562

34. Eskandari M, Hosseini SH, Adeli M, Pourjavadi A (2014) Polymerfunctionalized carbon nanotubes in cancer therapy: a review. Iran Polym J 23:387-403

35. Mallakpour S, Zadehnazari A (2013) The production of functionalized multiwall carbon nanotube/amino acid-based poly(amide-imide) composites containing a pendant dopamine moiety. Carbon 56:27-37

36. Mashhadzadeh AH, Fereidoon A, Ahangari MG (2017) Surface modification of carbon nanotubes using 3-aminopropyltriethoxysilane to improve mechanical properties of nanocomposite based polymer matrix: experimental and density functional theory study. Appl Surf Sci 420:167-179

37. Hu J, Li L, Feng W, Ji P (2012) Functionalization of carbon nanotubes regulated with amino acids. Colloid Surf A 407:16-22

38. Mallakpour S, Madania M (2015) A general and efficient route to covalently surface modification of MWCNTs by dopamine and their synergistic reinforcing effects inchitosan films. Prog Org Coat 85:131-137

39. Poskus LT, Lima RSMS, Lima IR, Guimarães JGA, da Silva EM, Granjeiro JM (2009) Cytotoxicity of current adhesive systems: in vitro testing on cell culture of L929 and balb/c 3T3 fibroblasts. Revista Odonto Ciência 24:129-134

40. Santos RL, Pithon MM, Martins FO, Romanos MTV, Ruellas ACO (2010) Cytotoxicity of latex and non-latex orthodontic elastomeric ligatures on L929 mouse fibroblasts. Braz Dent J 21:205-210

41. Hartman L, Lago RCA, Azeredo LC, Azeredo MAA (1987) Determination of hydroxyl value in fats and oils using an acid catalyst. Analyst 112:145-147

42. Wilczewska AZ, Niemirowicz K, Markiewicz KH, Car H (2012) Nanoparticles as drug delivery systems. Pharmacol Rep 64:1020-1037

43. Varshosaz J, Hassanzadeh F, Sadeghi-Aliabadi H, Larian Z, Rostami M (2014) Synthesis of Pluronic ${ }^{\circledR}$ F127-poly(methyl vinyl ether-altmaleic acid) copolymer and production of its micelles for doxorubicin delivery in breast cancer. Chem Eng J 240:133-146

44. Yuan F, Dellian M, Fukumura D, Leunig M, Berk DA, Torchilin VP, Jain RK (1995) Vascular permeability in a human tumor xenograft: molecular size dependence and cutoff size. Cancer Res 55:3752-3756

45. Zhang Y, Yang M, Portney NG, Cui D, Budak G, Ozbay E, Ozkan M, Ozkan CS (2008) Zeta potential: a surface electrical characteristic to probe the interaction of nanoparticles with normal and cancer human breast epithelial cells. Biomed Microdevices 10:321-328

46. Elimelech M, Chen WH, Waypa JJ (1994) Measuring the zeta (electrokinetic) potential of reverse osmosis membranes by a streaming potential analyzer. Desalination 95:269-286

47. Hunter RJ (1981) Zeta potential in colloid science: principles and applications. Academic Press, London 
48. Varshosaz J, Hassanzadeh F, Sadeghi Aliabadi H, Banitalebi M, Rostami M, Nayebsadrian M (2014) Novel worm-like amphiphilic micelles of folate-targeted cyclodextrin/retinoic acid for delivery of doxorubicin in KG-1 cells. Colloid Polym Sci 292:2647-2662

49. Varshosaz J, Taymouri S, Hassanzadeh F, HaghjooyJavanmard S, Rostami M (2015) Folatedsynperonic-cholesteryl hemisuccinate polymeric micelles for the targeted delivery of docetaxel in melanoma. Bio Med Res Int. https://doi.org/10.1155/2015/746093

50. Khosroushahi AY, Naderi-Manesh H, Yeganeh H, Barar J, Omidi Y (2012) Novel water-soluble polyurethane nanomicelles for cancer chemotherapy: physicochemical characterization and cellular activities. J Nanobiotechnol 10:1-15. https://doi. org/10.1186/1477-3155-10-2

51. Kim S, Shi Y, Kim JY, Park K, Cheng J (2010) Overcoming the barriers in micellar drug delivery: loading efficiency, in vivo stability, and micelle-cell interaction. Expert Opin Drug Dev 7:49-62

52. Lo C-L, Lin S-J, Tsai H-C, Chan W-H, Tsai C-H, Cheng C-HD, Hsiue G-H (2009) Mixed micelle systems formed from critical micelle concentration and temperature-sensitive diblock copolymers for doxorubicin delivery. Biomaterials 30:3961-3970

53. Kumari A, Yadav SK, Yadav SC (2010) Biodegradable polymeric nanoparticles based drug delivery systems. Colloids Surf B 75:1-18

54. McBane JE, Sharifpoor S, Cai K, Labow RS, Santerre JP (2011) Biodegradation and in vivo biocompatibility of a degradable, polar/ hydrophobic/ionic polyurethane for tissue engineering applications. Biomaterials 32:6034-6044
55. Guelcher SA, Srinivasan A, Hafeman AE, Gallagher KM, Doctor JS, Khetan S, McBride S, Hollinger J (2007) Synthesis, in vitro biocompatibility and biodegradation, and mechanical properties of two-component polyurethane scaffolds: effects of water and polyol composition. Tissue Eng 13:2321-2333

56. Rafiemanzelat F, Zonouz AF, Emtiazi G (2012) Synthesis and characterization of poly(ether-urethane)s derived from 3, 6-diisobutyl-2, 5-diketopiperazine and PTMG and study of their degradability in environment. Polym Degrad Stab 97:72-80

57. Loh XJ, Goh SH, Li J (2007) Hydrolytic degradation and protein release studies of thermogelling polyurethane copolymers consisting of poly [(R)-3-hydroxybutyrate], poly(ethylene glycol), and poly(propylene glycol). Biomaterials 28:4113-4123

58. Ponjavic M, Nikolic MS, Nikodinovic-Runic J, Jeremic S, Stevanovic S, Djonlagic J (2017) Degradation behaviour of PCL/PEO/ PCL and PCL/PEO block copolymers under controlled hydrolytic, enzymatic and composting conditions. Polym Test 57:67-77

59. Abdolmaleki A, Mallakpour S, Azimi F (2018) Microwave and ultrasound-assisted synthesis of poly(vinyl chloride)/riboflavin modified MWCNTs: examination of thermal, mechanical and morphology properties. Ultrason Sonochem 41:27-36

60. Van Krevelen DW (1975) Some basic aspects of flame resistance of polymeric materials. Polymer 16:615-620

61. Johnson RP (1974) A general correlation of the flammability of natural and synthetic polymers. J Appl Polym Sci 18:491-504 